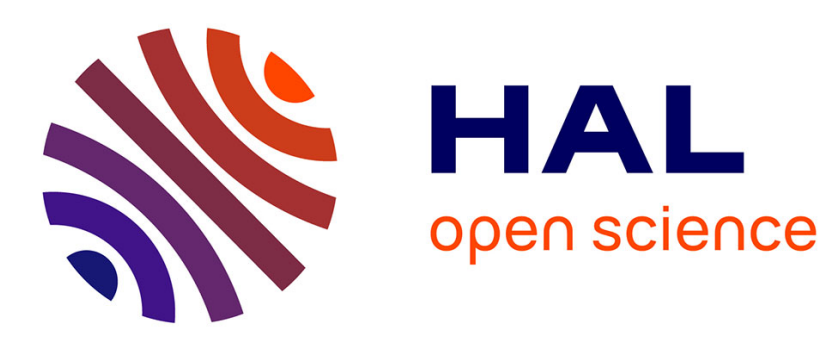

\title{
Determination of the crop row orientations from Formosat-2 multi-temporal and panchromatic images
}

Claire Marais-Sicre, Frédéric Baup, Rémy Fieuzal

\section{To cite this version:}

Claire Marais-Sicre, Frédéric Baup, Rémy Fieuzal. Determination of the crop row orientations from Formosat-2 multi-temporal and panchromatic images. ISPRS Journal of Photogrammetry and Remote Sensing, 2014, 94, pp.127-142. 10.1016/j.isprsjprs.2014.04.021 . ird-01061256

\section{HAL Id: ird-01061256 \\ https://hal.ird.fr/ird-01061256}

Submitted on 10 Sep 2014

HAL is a multi-disciplinary open access archive for the deposit and dissemination of scientific research documents, whether they are published or not. The documents may come from teaching and research institutions in France or abroad, or from public or private research centers.
L'archive ouverte pluridisciplinaire HAL, est destinée au dépôt et à la diffusion de documents scientifiques de niveau recherche, publiés ou non, émanant des établissements d'enseignement et de recherche français ou étrangers, des laboratoires publics ou privés. 
Provided for non-commercial research and education use. Not for reproduction, distribution or commercial use.

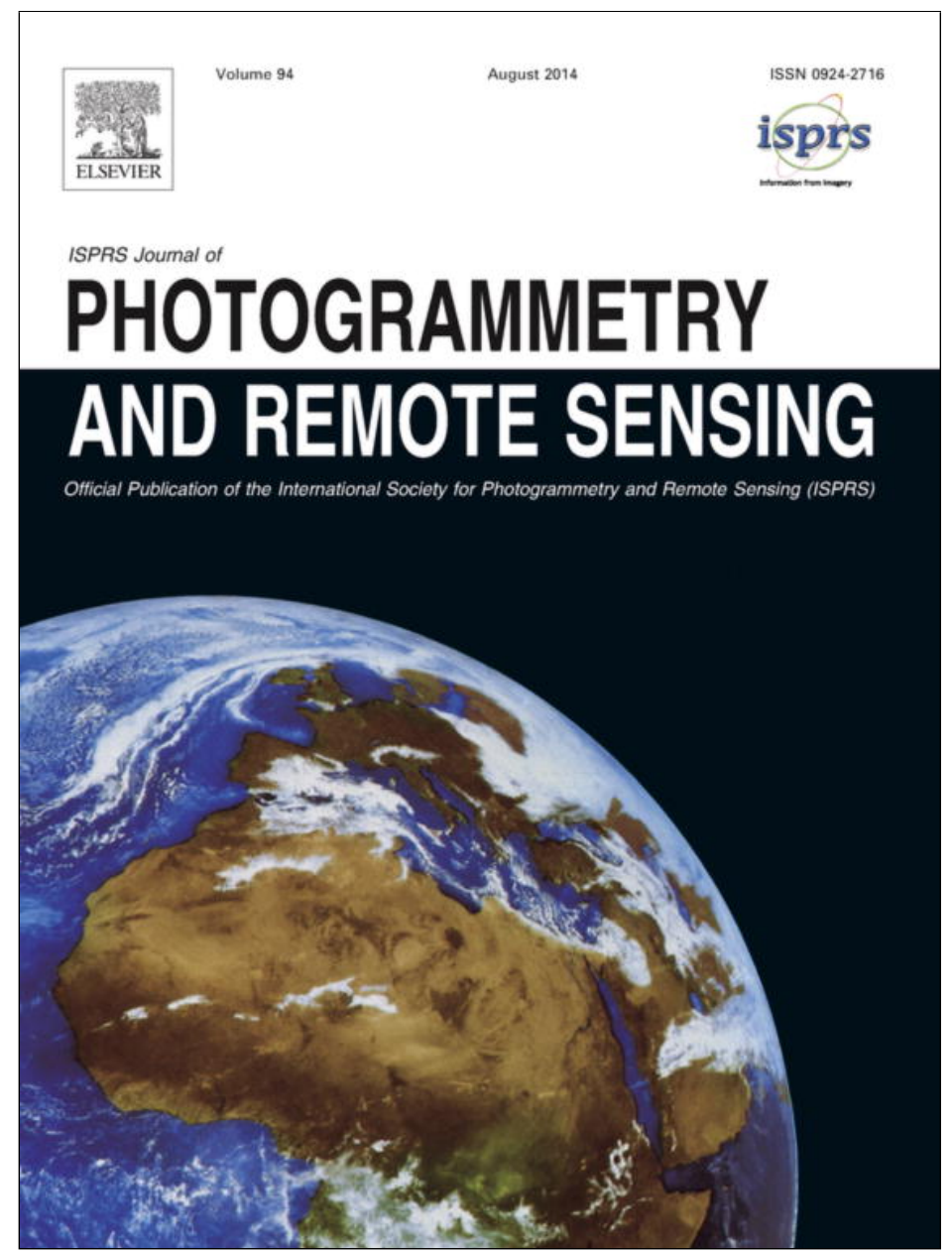

This article appeared in a journal published by Elsevier. The attached copy is furnished to the author for internal non-commercial research and education use, including for instruction at the authors institution and sharing with colleagues.

Other uses, including reproduction and distribution, or selling or licensing copies, or posting to personal, institutional or third party websites are prohibited.

In most cases authors are permitted to post their version of the article (e.g. in Word or Tex form) to their personal website or institutional repository. Authors requiring further information regarding Elsevier's archiving and manuscript policies are encouraged to visit: 


\title{
Determination of the crop row orientations from Formosat-2 multi-temporal and panchromatic images
}

\author{
Claire Marais Sicre*, Frédéric Baup, Rémy Fieuzal \\ Centre d'Etudes Spatiales de la BIOsphère (CESBIO), UMR 5126 (CNRS-CNES-IRD-UPS), Université de Toulouse, 18 Avenue E. Belin, Toulouse, France
}

\section{A R T I C L E I N F O}

\section{Article history:}

Received 28 October 2013

Received in revised form 20 February 2014

Accepted 24 April 2014

Available online 2 June 2014

\section{Keywords:}

Crop monitoring

Crop row orientation

Mathematical morphology

Directional filtering

Satellite image

Formosat-2

Panchromatic

\begin{abstract}
A B S T R A C T
This paper presents a technique developed for the retrieval of the orientation of crop rows, over anthropic lands dedicated to agriculture in order to further improve estimate of crop production and soil erosion management. Five crop types are considered: wheat, barley, rapeseed, sunflower, corn and hemp. The study is part of the multi-sensor crop-monitoring experiment, conducted in 2010 throughout the agricultural season (MCM'10) over an area located in southwestern France, near Toulouse. The proposed methodology is based on the use of satellite images acquired by Formosat-2, at high spatial resolution in panchromatic and multispectral modes (with spatial resolution of 2 and $8 \mathrm{~m}$, respectively). Orientations are derived and evaluated for each image and for each plot, using directional spatial filters $\left(45^{\circ}\right.$ and $\left.135^{\circ}\right)$ and mathematical morphology algorithms. "Single-date" and "multi-temporal" approaches are considered. The single-date analyses confirm the good performances of the proposed method, but emphasize the limitation of the approach for estimating the crop row orientation over the whole landscape with only one date. The multi-date analyses allow (1) determining the most suitable agricultural period for the detection of the row orientations, and (2) extending the estimation to the entire footprint of the study area. For the winter crops (wheat, barley and rapeseed), best results are obtained with images acquired just after harvest, when surfaces are covered by stubbles or during the period of deep tillage $\left(0.27>R^{2}>0.99\right.$ and $7.15^{\circ}>$ RMSE $\left.>43.02^{\circ}\right)$. For the summer crops (sunflower, corn and hemp), results are strongly crop and date dependents $\left(0>R^{2}>0.96,10.22^{\circ}>\operatorname{RMSE}>80^{\circ}\right)$, with a well-marked impact of flowering, irrigation equipment and/or maximum crop development. Last, the extent of the method to the whole studied zone allows mapping $90 \%$ of the crop row orientations (more than $45,000 \mathrm{ha}$ ) with an error inferior to $40^{\circ}$, associated to a confidence index ranging from 1 to 5 for each agricultural plot. (c) 2014 International Society for Photogrammetry and Remote Sensing, Inc. (ISPRS). Published by Elsevier
\end{abstract}

B.V. All rights reserved.

\section{Introduction}

Agricultural land is a significant source of concern, as a consequence of the natural resources it uses (water), and which it produces (food). Thanks to their broad spatial coverage, their objectivity and their wide range of acquisition wavelengths, satellite images have been widely used to monitor those continental surfaces at different scales (from plot to national scales) (Bastiaanssen et al., 2000; Dabrowska-Zielinska et al., 2002; Seelan et al., 2003; Duchemin et al., 2006; Hadria et al., 2009; Mc Nairn et al., 2009; Claverie et al., 2012; Moran et al., 2012; Fieuzal et al., 2013). It is nevertheless still challenging to estimate its biophysical parameters, as a result of the complex nature of agrosystems. This limitation is mainly attributed to the cross con-

\footnotetext{
* Corresponding author. Tel.: +33 610928551.

E-mail address: claire.marais-sicre@cesbio.cnes.fr (C. Marais Sicre).
}

tribution of surface properties involved in the satellite reflectance signal (crop heterogeneity, surface slope, soil type, crop row direction, etc.) (Baret et al., 2010; Zhao et al., 2010; Agam et al., 2012). An improvement in the monitoring of crops thus partially relies on the ability to detect and interpret the properties of an agricultural surface, in particular the direction in which the plot is worked (associated either with tillage practices, crop management from seedling to harvest, swaths, tracks from the agricultural machinery, etc.). The crop row orientation influence has been demonstrated in several wavelength domains (ranging from the optical to microwaves), through the use of bidirectional reflectance distribution functions (BRDF), with respect to the viewing angle of the satellite images (Ulaby and Bare, 1979; Dobson and Ulaby, 1981; Kimes and Kirchner, 1983; Ulaby et al., 1984; Dobson et al., 1995; Champion and Faivre, 1996; Andrieu et al., 1997). It is thus important to take the row orientation into account in the physical or empirical methods used to improve the estimate of the biophysical parameters of 
the crops (biomass, yield, leaf area index, water content, etc.) (Loseen et al., 1995; Lobell et al., 2003; Wessels et al., 2006; Duchemin et al., 2008; Liu et al., 2010; Claverie et al., 2012; Fieuzal et al., 2012) and of the soil (moisture, runoff, risk of erosion, etc.), through the use of satellite (Turner, 1989; Gaillard, 2001).

At landscape, the orientation of the tillage or crop present strong spatial heterogeneities, resulting from the farmer's preferences, the topological parameters of the plots (shape, size, or slope), the variety of cultivated crops and growth patterns, and also from the management of agricultural practices (soil preparation and tillage, seedlings, harvesting, irrigation, etc.). On a satellite image, those orientations (also defined as lineaments) take the form of lines or curves, which are the visual manifestation of the orientation of rows of crops or inter-plot heterogeneities. From the wide range of techniques which could be used to detect the lineaments, mathematical morphology appears a well-adapted method for the extraction of linear networks because it is both based on the spectral properties of the images (signature or texture), and their spatial and contextual characteristics (shape, size, topological relationship or proximity). Although this technique has never been applied to agricultural plots, it has been widely applied for the extraction of urban zones, roads, coastlines and various different landscape features (Callot et al., 1993; Zheng et al., 1995; Brunn and Weidner, 1998; Zhang et al., 1999; Laporterie and Flouzat, 2001; Jishuang and Chao, 2002; Matti-Gallice and Collet, 2004; Jin and Davis, 2005; Sheeren et al., 2007; Valero et al., 2010; Maire et al., 2012). The application of the mathematical morphology to satellite images will allow the detection the row orientation over the entire swath of the images, today limited to one-plot approach thanks to the use of vision system installed onboard of mobile agricultural vehicle in the context of precision agriculture (Olsen, 1995; Marchant, 1996; Hague and Tillett, 2001; Sogaard and Olsen, 2003; Bobillet et al., 2003; Gée et al., 2008; Bossu et al., 2009; Jones et al., 2009; Wu et al., 2011;
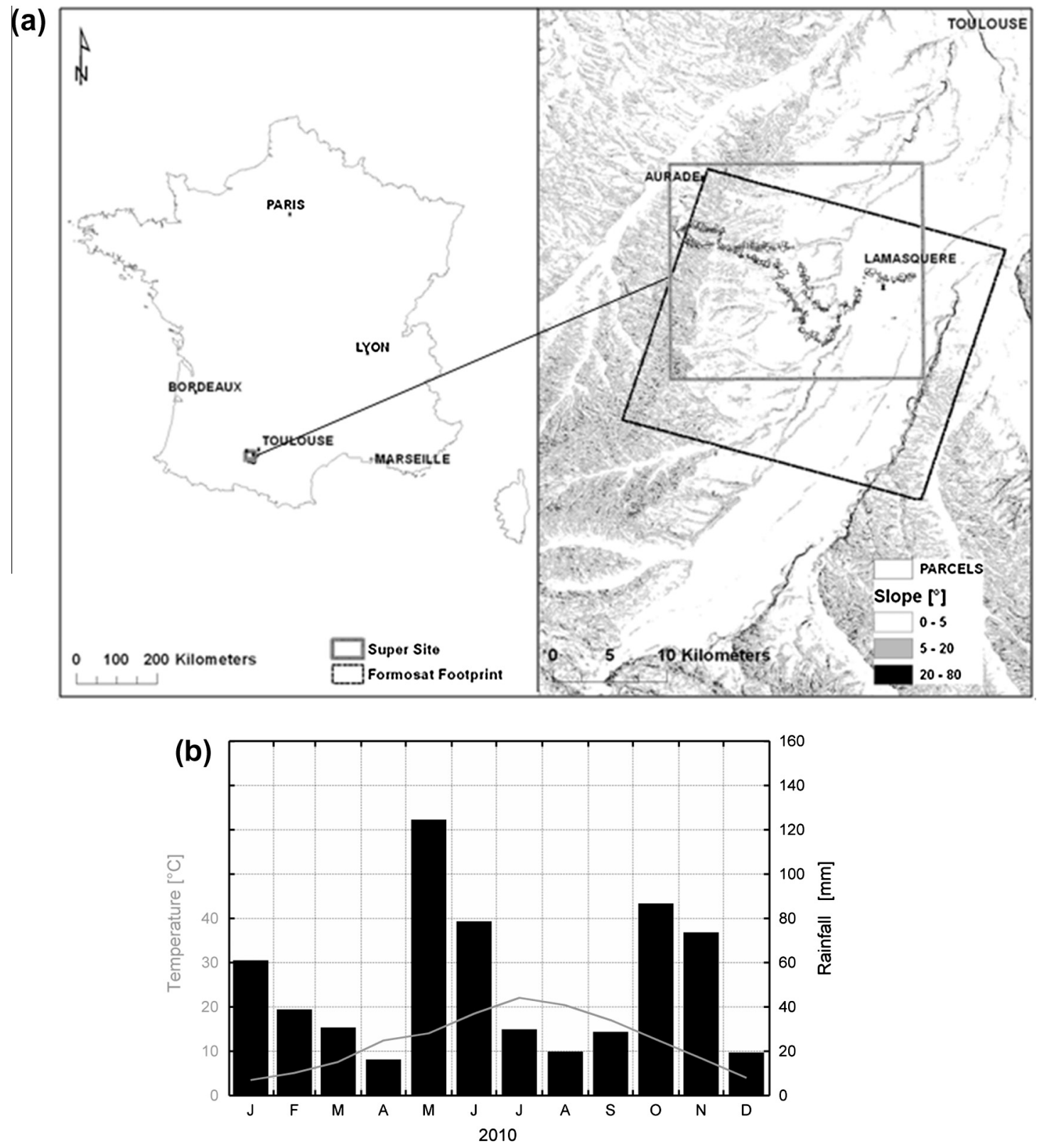

Fig. 1. (a) Localization of the study site ("super site") in the South West of France with the location of the 232 studied plots. (b) Ombrothermic diagram of the year 2010. Monthly mean air temperatures (in grey) and cumulative precipitations (in black) are derived from the meteorological station of Lamasquère. 


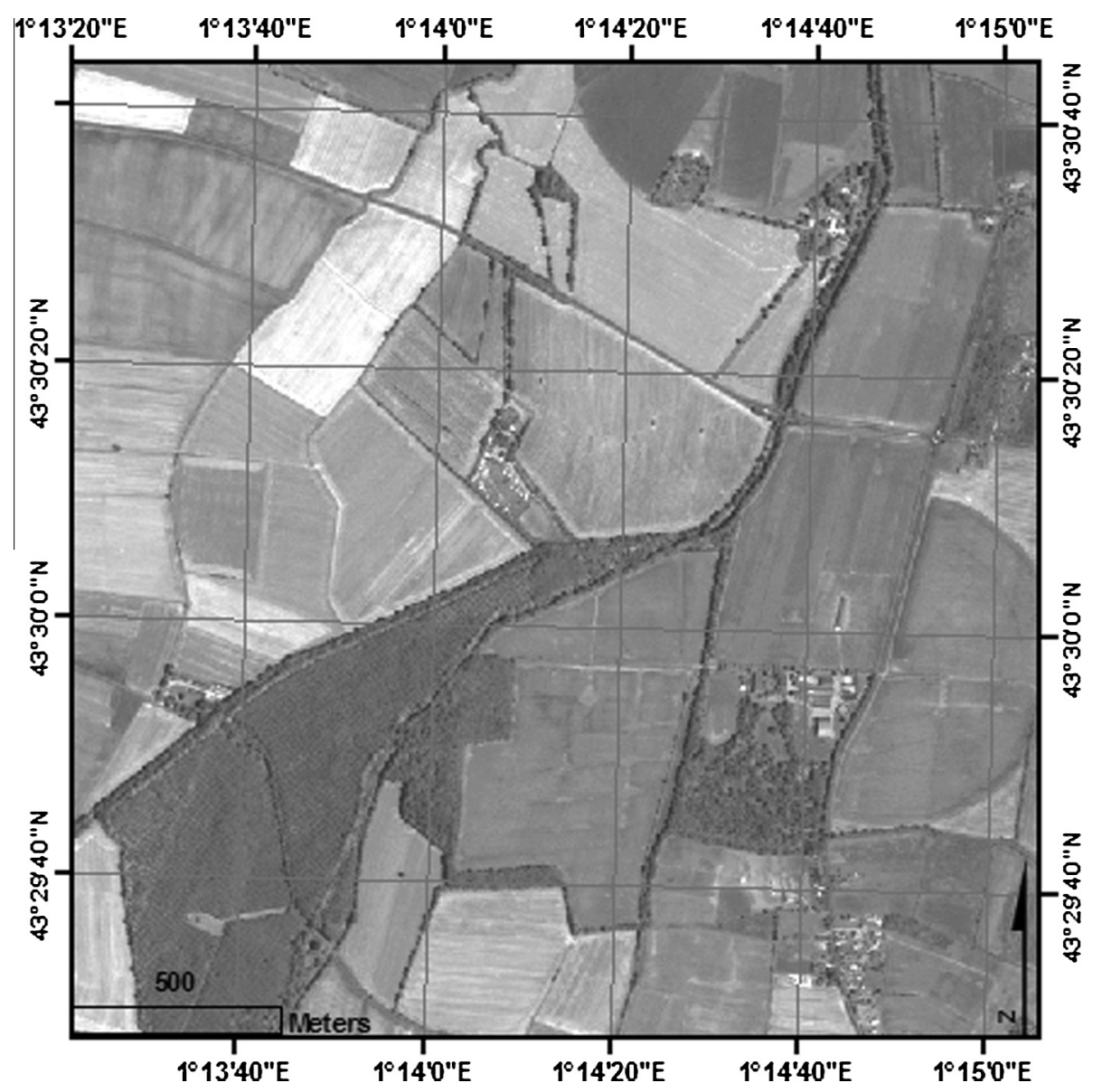

Fig. 2. Panchromatic image acquired on July 19th, 2010.

Table 1

Temporal distribution of the images acquired in the multi-spectral (MS) and panchromatic (PAN) modes.

\begin{tabular}{lllll}
\hline Sensor Mode & \multicolumn{4}{l}{ Acquisition dates (year 2010) } \\
\hline & 2-Mar & 21-May & 8-Aug & 21-Oct \\
MS & 10-Apr (just PAN) & 07-Jul (just PAN) & 27-Aug & \\
PAN & 18-Apr & 19-Jul & 15-Sep & \\
& 27-Apr & 31-Jul & 7-Oct & \\
\hline
\end{tabular}

Burgos-Artizzu et al., 2011; Montalvo et al., 2012; Guerrero et al., 2013).

Among the wide range of available satellite images, it is assume to explore the capability of high spatial resolution images (HSR), since they represent a suitable compromise between the remote sensor's temporal sampling capabilities (few days), the spatial resolution $\left(R_{S P A}<10 \mathrm{~m}\right.$, compatible with the size of agricultural plots) and the associated swath widths $(>20 \mathrm{~km})$. The use of HSR images is preferred to very high spatial resolution images (VHSR, $R_{S P A}<1$ $\mathrm{m})$ for which, its characteristics do not currently allow multi-temporal and medium swath techniques to be implemented. On the other hand, low-resolution satellite images (several $\mathrm{km}$ ), like those provided by SMOS, ASCAT, AMSR, etc., are not used in this study because of the small size of the surface elements to detect.

In this context, the aim of the present study is to develop and apply a multi-temporal approach to extract the crop row orientations over agricultural landscape, through the use of high resolution images delivered by the satellite Formosat-2. The paper is structured as follows: main characteristics of the studied site are first presented (section 1) followed by the description of satellite images and ground data acquired during the MCM'10 Experiment
(Section 2). Section 3 describes the methodology used to estimate the crop row orientations. Analyses and results are discussed in Section 4, by considering single-date and multi-temporal approaches. This section includes (1) the determination of the periods which are the most suitable for the row extraction (in link with the crop phenological cycles and/or the agricultural practices) and (2) a row orientation map performed over the entire image footprint. Conclusions and prospects are provided in Section 5.

\section{The study site}

The French landscape is strongly dependent on the history of its society and the techniques which have been used over time. The morphology of its land plot network can be traced back to a selforganized network from the Middle Ages (Latouche, 1967). Thus, agricultural plots throughout the country are very diverse in terms of their size and shape despite agricultural reparcelling which began in 1941. The studied site, defined as "super-site", is part of this heritage (Fig. 1a). It is situated in the South-West of France, near Toulouse (central coordinates: $43^{\circ} 29^{\prime} 36^{\prime \prime} \mathrm{N}, 1^{\circ} 14^{\prime} 14^{\prime \prime} \mathrm{E}$ ). It is governed by a temperate climate and includes two meteorological stations near to the villages of Lamasquère and Auradé. The annual rainfall amounted to $600 \mathrm{~mm}$ in 2010 (with a maximum of $125 \mathrm{~mm}$ in May). The average daily air temperature ranges from a few degrees in winter to $25^{\circ} \mathrm{C}$ in summer (Fig. 1b). In this region of alluvial plains and hills, the steepest slopes are mainly found in the transition zones, between low (174 m) and medium (319 m) altitudes. They never exceed $13.4^{\circ}$.

The super site is oriented toward polyculture/livestock, and is composed of crops (56.8\%), forests (7.9\%), urban areas $(2.4 \%)$, 
$\stackrel{N}{N}$

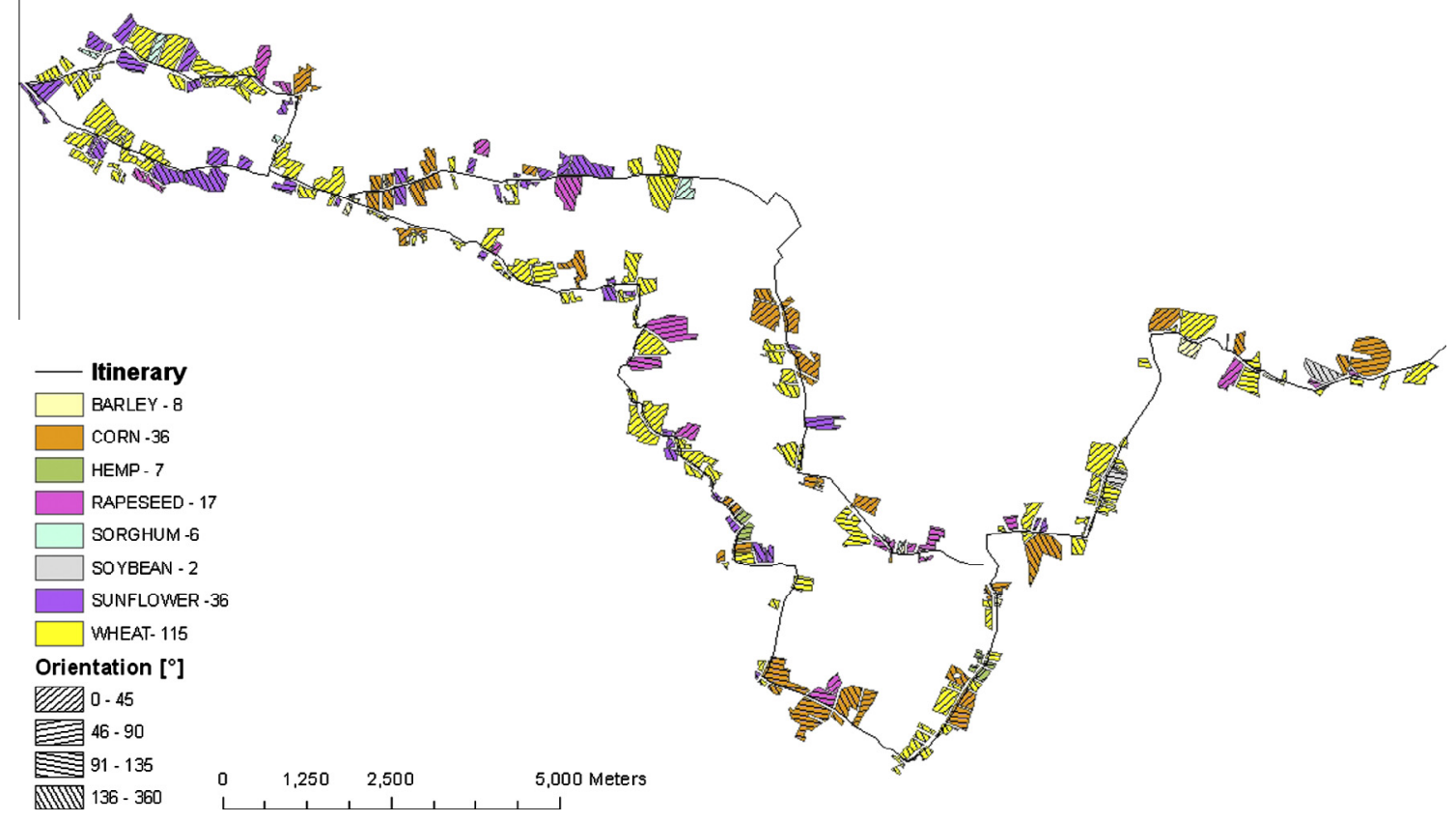

Fig. 3. Spatial distribution of crop types and associated orientations.

Table 2

Number of observed crop type and mean crop spacing.

\begin{tabular}{lcl}
\hline Crop type & Numberof plot & Mean crop spacing $(\mathrm{cm})$ \\
\hline Wheat & 115 & 20 \\
Rapeseed & 17 & 80 \\
Barley & 8 & 20 \\
Corn & 36 & 80 \\
Sunflower & 36 & 80 \\
Hemp & 7 & 80 \\
Sorghum & 6 & 80 \\
Soybean & 2 & 80 \\
Ray grass & 4 & 20 \\
Pea/Soybean & 1 & \\
\hline
\end{tabular}

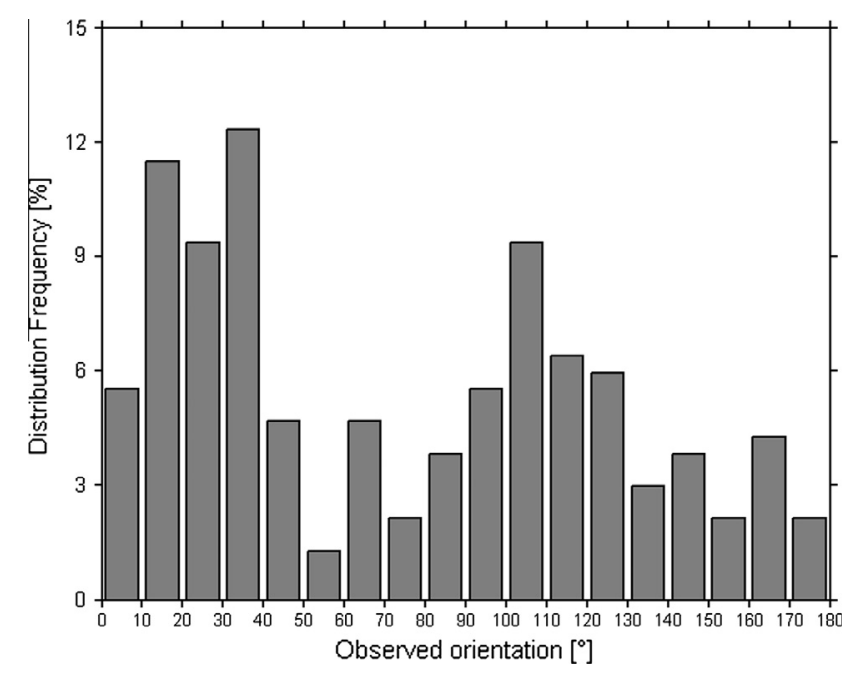

Fig. 4. Distribution of crop row orientations on the 232 observed plots. grasslands (32.1\%) and water bodies (0.8\%). The crops are various and their rotation is typical of temperate regions. They are divided in two categories: winter (wheat, barley and rapeseed) and summer crops (corn, sunflower, sorghum, soybean, hemp). Few other crops are also present in the super-site, but not considered in this study (peas, beans, etc.). The winter crops of wheat and barley emerge in autumn, followed by a latency phase in winter and new growth in spring. Ear emergence occurs in May/June and harvesting takes place in summer. Barley is sown at the same time than wheat, but generally matures earlier. A small number of late barley varieties emerge in spring, and are harvested at the end of the summer. Rapeseed has a long vegetation cycle (emergence in September, flowering in April/May and harvesting in July). Despite a strong heterogeneity in its development during the growing season, the vegetation can fully covers soil at the end of flowering (Boissard et al., 1992; Denoroy et al., 2000).

The sunflower has a short vegetation cycle lasting between 120 and 150 days, depending on its variety and on climatic conditions. Emergence occurs between April and June, and harvesting begins at the end of summer and continues throughout the autumn. The plots are often heterogeneous in term of vegetation development and density. The emergence of corn, soybean and sorghum begins at the end of April, with harvesting ranging from October to November. Approximately $90 \%$ of corn and soybean crops in the monitored zone are irrigated. The emergence of hemp also takes place at the end of April, and in May the vegetation cover is high (about 90\% three weeks after emergence). Flowering begins in June, and harvest takes place in September.

\section{Satellite and ground data}

\subsection{Satellite images}

The images are provided by the Taiwanese satellite Formosat-2, which was launched in May 2004 on a sun-synchronous orbit. It 


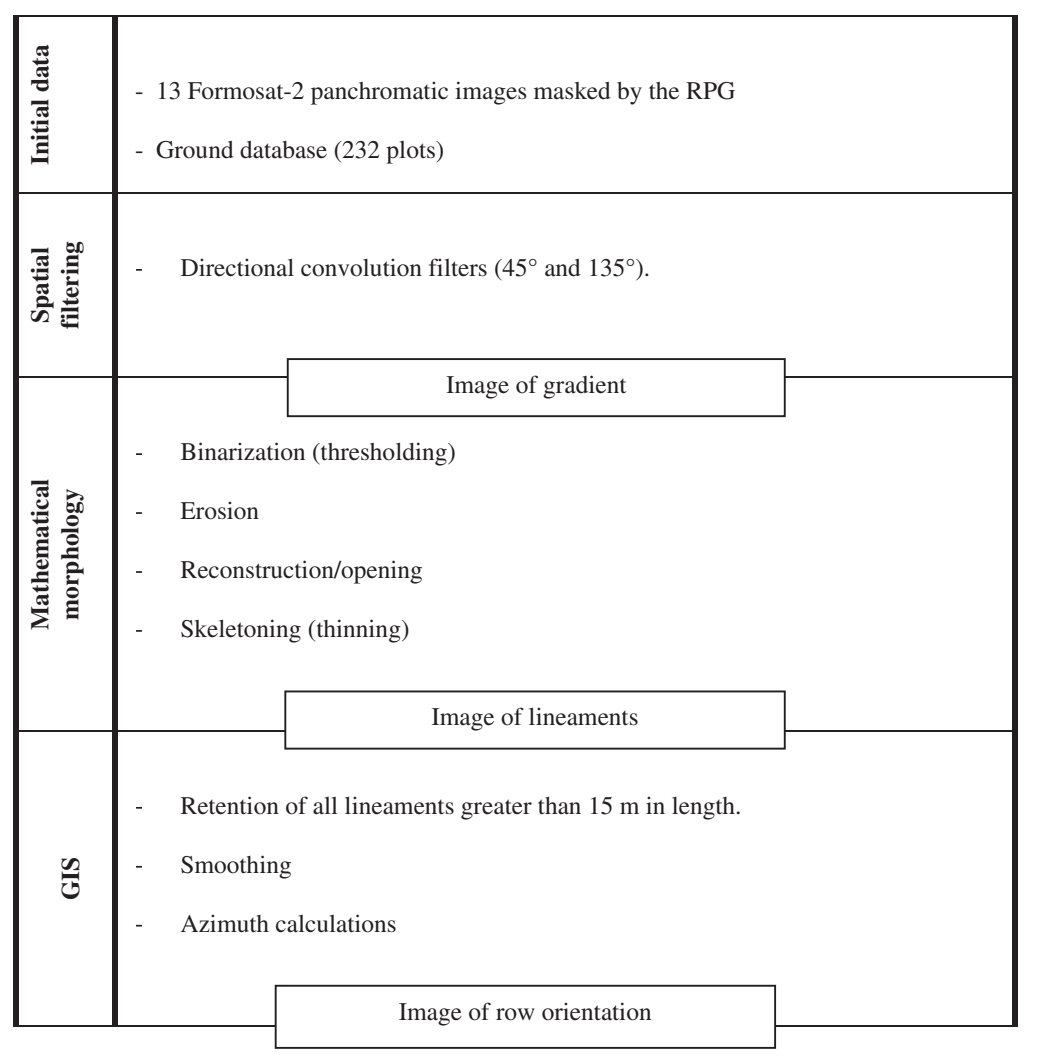

Fig. 5. Description of the method used to estimate the lineament orientations of an agricultural landscape.

produces optical images using barrette sensors (in the visible and short-wave infrared domains) at HSR ( $8 \mathrm{~m}$ in multi-spectral and $2 \mathrm{~m}$ in panchromatic modes), with a constant viewing angle: $45^{\circ}$ lateral and $45^{\circ}$ forward-backward looking (Chern et al., 2006). Each image covers a $24 \times 24 \mathrm{~km}^{2}$ area centered on the super-site. They are processed by the CNES in the framework of the "Kalidéos" program (Rabaute et al., 2012) (Fig. 1a). All the images are orthorectified using CNES ortho-rectification tools. Cloud detection and atmospheric correction are also applied. The mean location accuracy is about one pixel. Images acquired in multispectral mode are radiometrically corrected to the top of the canopy (TOC), whereas the panchromatic images are corrected to the top of the atmosphere (TOA).

The multispectral (MS) mode is used to generate Normalized Difference Vegetation Index (NDVI) images, in order to monitor the crop cycle ( 11 images are available in this mode). The reprocessed panchromatic images (PAN) are used to detect the crop row orientations (Fig. 2). The 13 satellite images are acquired between March 2nd and October 21st, 2010 (Table 1).

\subsection{Ground data}

Ground data are collected between February 20th and November 23rd, 2010, within a $252 \mathrm{~km}^{2}$ zone, during the Multispectral Crop Monitoring'10 experiment (Baup et al., 2012). They concern the observation of the land and its heterogeneities, the soil tillage (type and orientation), plot exposure and plot slope (Meier, 2001). Data are regularly collected along a $70 \mathrm{~km}$ itinerary, which allows sampling the variability of surface parameters as shown in Fig. 3.

The 232 sampled plots are characterized by a wide variety of geometric shapes (square, rectangular, circular or triangular) and sizes ranging from 0.14 to 24.6 ha. Mean local slopes range between $0^{\circ}$ and $13.4^{\circ}$. The crops are usually sown in rows at a constant spacing ranging from approximately $12 \mathrm{~cm}$ to $85 \mathrm{~cm}$ (respectively for wheat and rapeseed for example).

In $2010,60 \%$ of the monitored plots are winter crops (610 ha) and $40 \%$ are summer crops ( $460 \mathrm{ha}$ ). The number of plots observed as a function of the type of crop is summarized in Table 2. The orientation-related information is recorded for 232 plots, of which 227 are sown with one of the principal crops (140 with winter crops and 87 with summer crops) and 5 others are either temporary meadows (ray grass, etc.), pea or soya bean crops (Table 2). Those last 5 plots are integrated into the study of all of the crops, however as a result of their small number they can not be studied specifically.

The orientation of the seedling rows is measured with a compass $\left( \pm 5^{\circ}\right)$, just after the emergence, when the low vegetation cover allows the observation of the lineaments. Fig. 4 shows the histogram of observed orientations, for the full set of 232 plots. The azimuths cover the full range of angles between 0 and $180^{\circ}$, with a bimodal distribution centered on $25^{\circ}$ and $105^{\circ}$. No significant relationship is observed between the plots exposure or slope, and the orientation (the coefficients of determination between those parameters are close to 0.1 ).

\subsection{Exogenous data}

Since 2007, the French Services and Payment Agency (ASP) provide a regulated anonymous version of graphical data from the French Graphical land Plot Register (RPG), associated with the data declared by the French farmers. This layer of information is used for the management of European land surface subsidies. The $R P G$ is a geographical information system, which supplies detailed information concerning land use and standing structures. It is used in the present study as a mask layer, in order to restrict the analysis to cultivated areas only. 


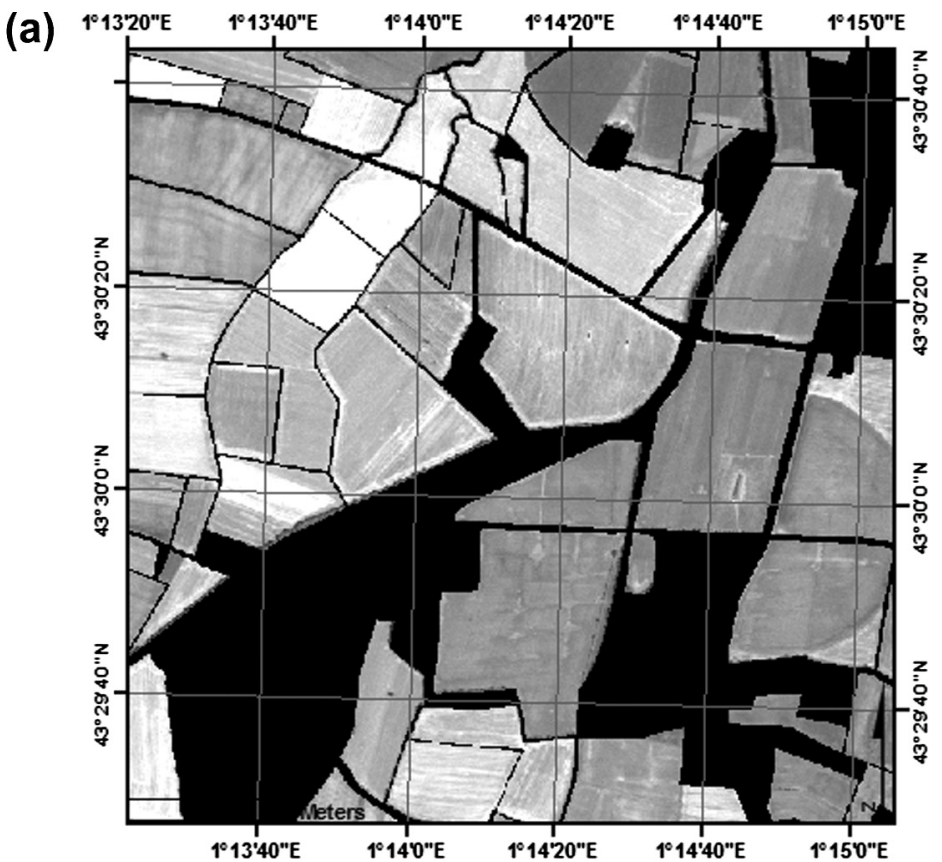

(b)

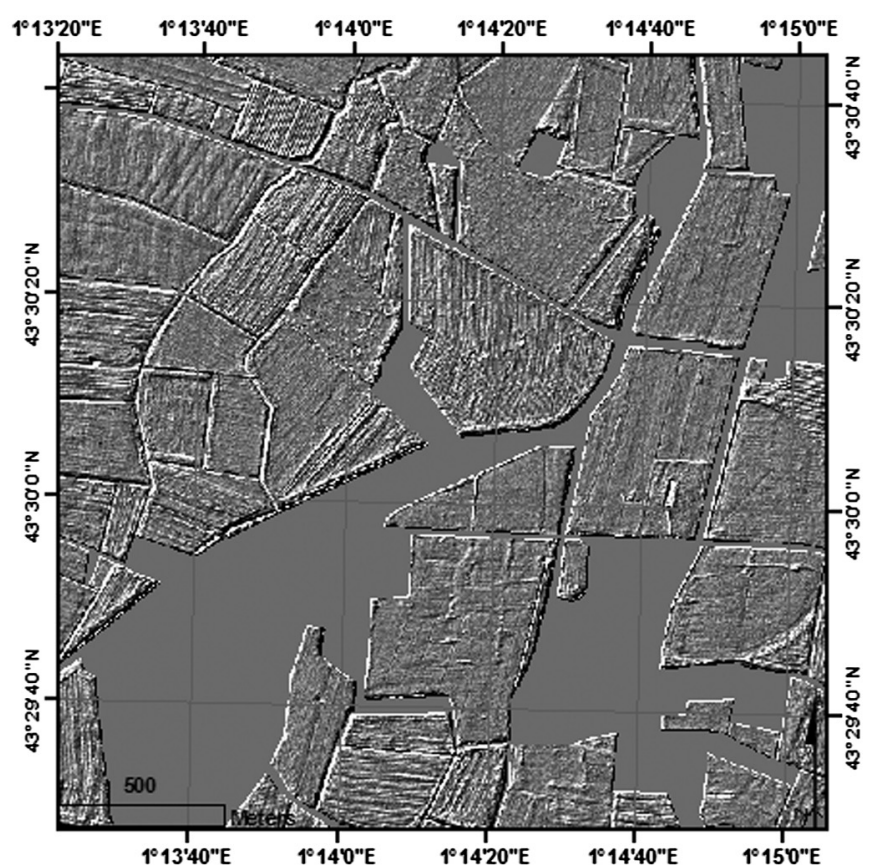

(c)

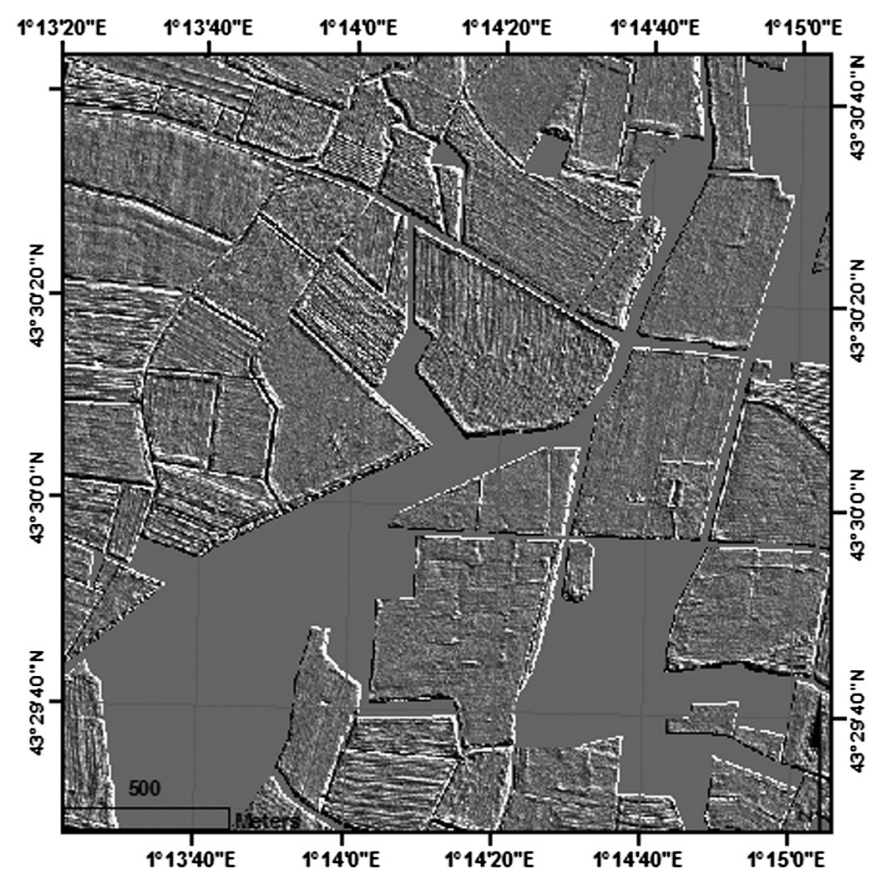

Fig. 6. Examples of filtering images processed at $45^{\circ}$ (b) and $135^{\circ}$ (c) estimated from the initial panchromatic image acquired on 19 th of July (a). Masked areas are displayed in black.

\section{Methodology}

The applied technique is designed to extract all the plot row orientations from the 13 panchromatic images (Fig. 5). A directional convolution filter is first applied in order to produce 8 bits gradient images (using the default weighting coefficients of the ENVI 4.7 software). The filter's convolution kernel is a $3 \times 3$ window, applied in 2 different directions: $45^{\circ}$ and $135^{\circ}$. The filtering allows the extraction of the textural information related to the lineament grid. The lineaments aligned in the direction of the filter are highlighted (Fig. 6), thus simplifying the use of mathematical morphology extraction techniques. The use of a succession of morphological operations (erosion, geodesic reconstruction, opening and skeletoning) on the gradient image makes it possible to obtain an image of the lineament grid (Fig. 7). Azimuth extraction is carried out in Geographic Information Systems (GIS) software (Fig. 8).

The final step involves the selection of the results produced by the 2 filters, corresponding to several different dates, in order to produce a seedling row orientation map of the studied zone. 

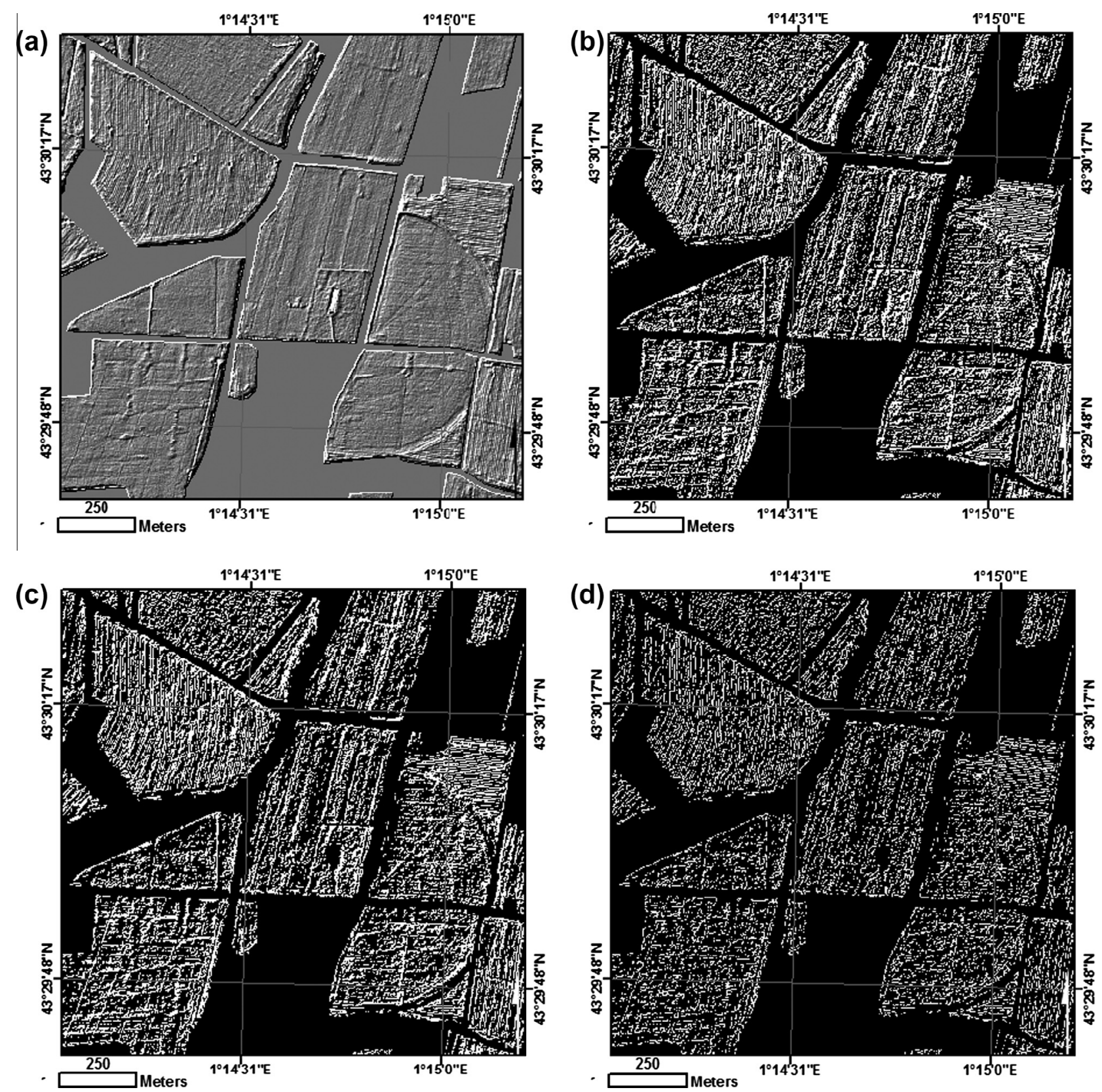

Fig. 7. Image processing is composed of 4 steps (a) Image produced by a $45^{\circ}$ directional filter; (b) Binary image obtained by thresholding; (c) Erosion, reconstruction/opening of 2 pixels on a thresholded image; (d) Skeletoning.

(a)

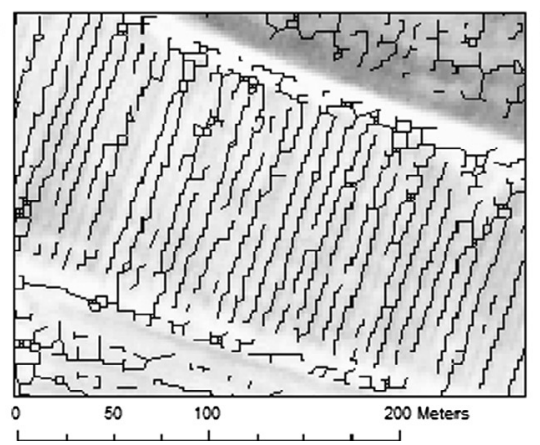

(b)

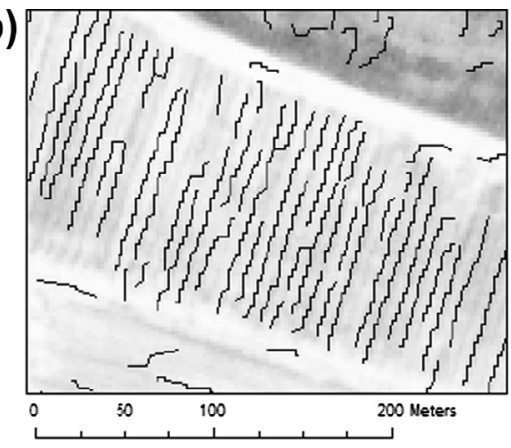

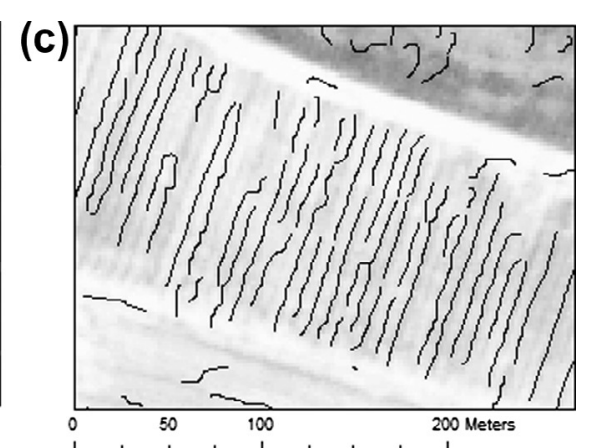

Fig. 8. Example of lineament obtained by: skeletoning (a); after eliminating lines inferior to $15 \mathrm{~m}$ (b), and after smoothing the lines (c). 
(a)

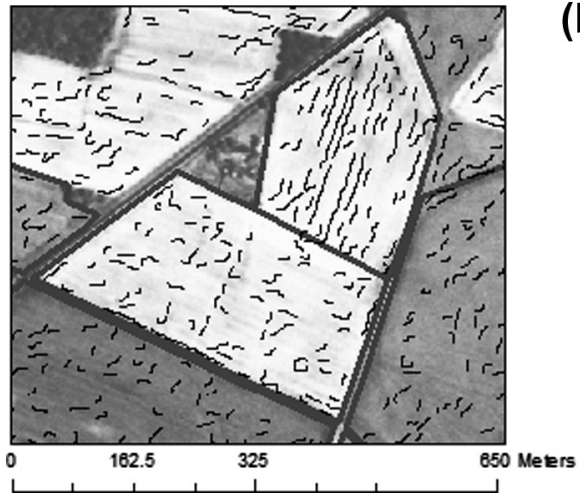

(b)

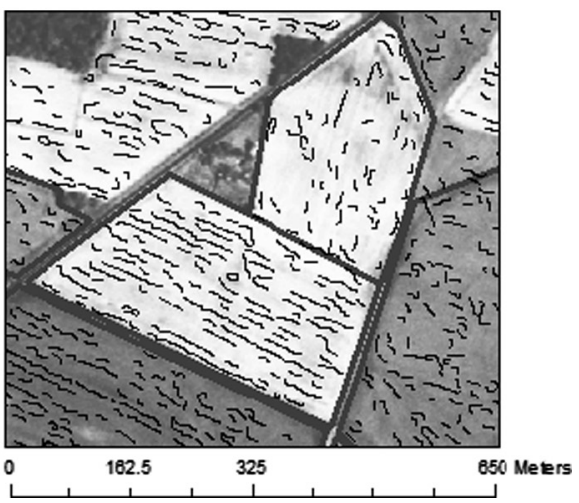

Fig. 9. Example of lineaments determined by the $45^{\circ}$ directional filter (a) and by the $135^{\circ}$ directional filter (b) on a panchromatic image recorded on July 19 th, 2010 .
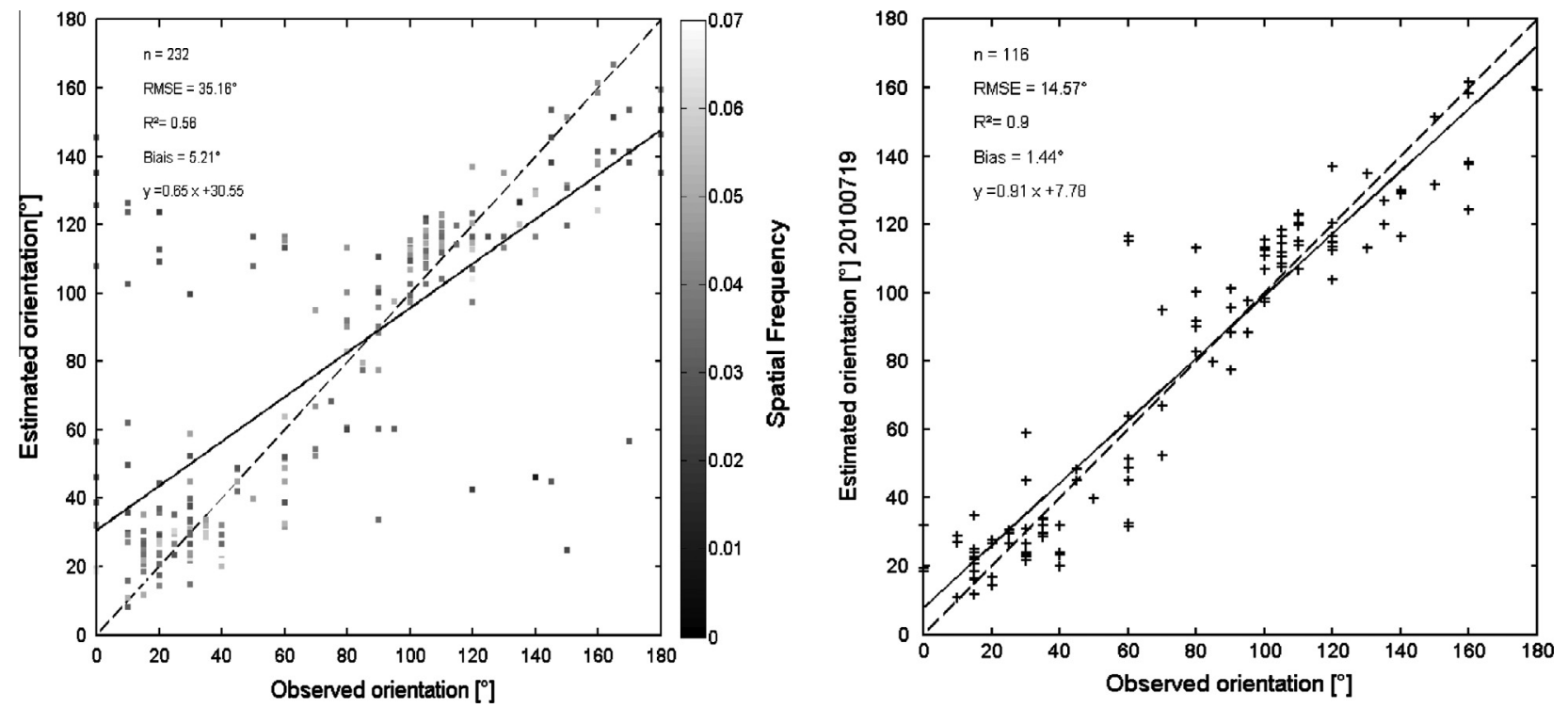

Fig. 10. Comparison between observed and calculated orientations, for all crops on July 19th, 2010; before and after applying a threshold on the spatial frequency (respectively (a) and (b)).

Table 3

Evaluation of the technique's performances to detect the row orientations, as a function of crop type (July 19th).

\begin{tabular}{llllll}
\hline & $n$ (parcel) & $R^{2}$ & RMSE $\left({ }^{\circ}\right)$ & rRMSE (\%) & FD (\%) \\
\hline All crops & 116 on 232 & 0.90 & 14.57 & 19.98 & 50.00 \\
Winter crops & 92 on 140 & 0.91 & 14.66 & 20.98 & 65.71 \\
Wheat & 77 on 115 & 0.90 & 14.8 & 21.19 & 66.96 \\
Barley & 5 on 8 & 0.99 & 8.41 & 10.64 & 62.50 \\
Rapeseed & 10 on 17 & 0.87 & 15.99 & 24.42 & 58.82 \\
Summer crops & 20 on 87 & 0.90 & 1.30 & 15.97 & 19.23 \\
Corn & 8 on 37 & 0.95 & 11.11 & 12.51 & 22.22 \\
Sunflower & 4 on 36 & 0.92 & 18.52 & 31.52 & 11.11 \\
Hemp & 5 on 7 & 0.96 & 12.53 & 13.77 & 71.43 \\
Sorghum & 3 on 6 & 0.99 & 11.73 & 8.99 & 50.00 \\
Soybean & 0 on 2 & - & - & - & 0.00 \\
\hline
\end{tabular}

\subsection{Spatial filtering}

The panchromatic images reveal a texture characterized by a repetitive grid on the agricultural plots (Fig. 6). The directional filtering highlights this lineament grid, within a range of orientations defined by the filter's sensitivity $\pm 45^{\circ}$ (Zall and Russel, 1979; Amesz and Lausink, 1984; Mavrantza and Argialas, 2003). Fig. 6 shows the images obtained with the $45^{\circ}$ and $135^{\circ}$ directional filters, applied on an image acquired on July 19th with a mobile
$3 \times 3$ filtering window (masked areas are displayed in black). When used together, the 2 filters allow covering an angular distribution varying between $0^{\circ}$ and $180^{\circ}$, which corresponds to the full range of possible orientation of plots at landscape.

\subsection{Extraction of lineaments}

Lineaments extraction is performed by using algorithm of mathematical morphology ("set operation" as defined by Serra, 1988). This technique requires the application of morphological operators to binary images, through the use of a mask or a predefined geometrical pattern: the structuring element. This can have several different shapes (square, rectangle, circle, etc.). Binarization is performed by thresholding the 8 -bits gradient directional images produced by the spatial filtering. Minimum and maximum thresholds are set for all the images and are respectively equals to 170 and 255. The resulting binary image has only a restricted range of gradients, representative of the lineaments. The value of the output pixels is thus equal to 1 between the lower and upper limits of the thresholding, and is equal to zero everywhere else. The basic binary image is shown in Fig. 7b. This image has been eroded and the disk ( 2 pixels) has been selected as a structuring element. Isolated pixels are then eliminated and a marker image is obtained. However, the erosion also reduces the size of the objects present in 


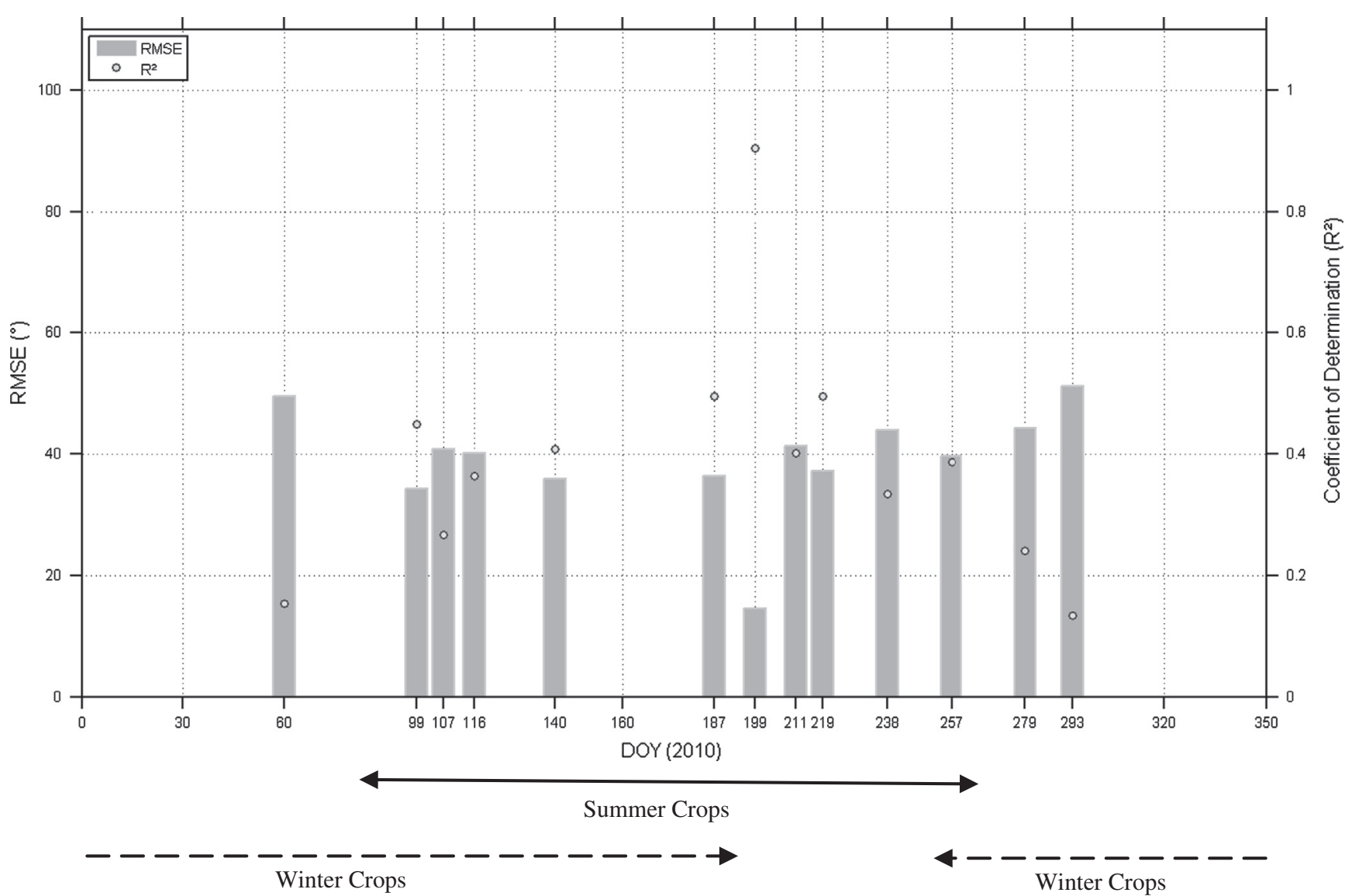

Fig. 11. Temporal evolution of the coefficient of determination and the mean square error, associated with the estimation of land plot orientation (for all types of crop).

the image. Geodesic reconstruction is thus applied (followed by opening operation), with the aim of eliminating small connected lineaments while maintaining the original shape of objects. (Fig. 7c).

These various operations are completed by skeleton calculations based on thinning. The skeletoning allow the shape of part of a binary image to be reduced to a "line", while preserving its topological characteristics (Fig. 7d).

\subsection{Orientation extraction and calculation}

This GIS processing is carried out both with tools embedded in ESRI's ArcGIS (version 10) software, for the calculation of geometric attributes, and with a free application developed for ArcGIS by Jenness Entreprises (Jenness, 2011).

The skeletons obtained from mathematical morphology (Fig. 8a) are refined and the elements perturbing the orientation determinations are eliminated. Only the skeletons greater than $15 \mathrm{~m}$ in length are kept, in order to eliminate various islands and outcrops (Fig. 8b). The skeletons are then smoothed using the PEAK (Polynomial Approximation with Exponential Kernel) method implemented in the ArcGIS 10 software (a threshold tolerance of 10 is set) (Fig. 8c). The orientation angle is finally defined as the direction of a lineament with respect to the North (clockwise).

The results are evaluated on the basis of a comparison between the azimuths estimated for each plot and for each filter $\left(45^{\circ}, 135^{\circ}\right)$, and those measured in the plot. The use of satellite images thus made it possible to extract the following information for each plot: the quantity of lineaments, length of the lineaments (L), surface area (S), and median of the estimated orientation.

When the range of orientations covered by the filter includes that of the observed crop row, the lineament density determined for the plot is greater (Fig. 9). For a given plot " $i$ ", the choice of the orientation given by the 2 filters is based on the analysis of the spatial frequency $(S F)$, defined as:

$S F_{\alpha}^{i}=\frac{L_{\alpha}^{i}}{S^{i}}$

where $L$ represents the total length of the lineaments inside a plot, $S$ and $i$ are respectively the surface (provided by RPG data) and the identifier of the plot. $\alpha$ represents the angle of the filter $\left(45^{\circ}\right.$ or $\left.135^{\circ}\right)$. $S F$ is expressed in $\mathrm{m}^{-1}$.

For each plot, when the spatial frequency defined by the $45^{\circ}$ filter is greater than or equal to that given by the $135^{\circ}$ filter, the orientation determined by the $45^{\circ}$ filter is retained, and vice versa.

\section{Results and discussion}

The methodology is applied to the time series of 13 images through two interconnected approaches: single-date (Section 4.1) and multi-date (Section 4.2) processing. Single-date approach is used to validate the method, by estimating the contributions of each directional filter. Multi-date analysis is used to quantify the contribution of each date, for each type of culture, to estimate the crop row orientation. Results produced by the multi-temporal technique make then it possible to extend the intra-land-plot orientation to the full extent of the scene (Section 4.3).

\subsection{Single-date analysis}

Single-date analysis is carried out on the image acquired on 19 th of July. At this date, all the summer crops are growing, and are at different phenological stages. Most of the winter crops 
(a)
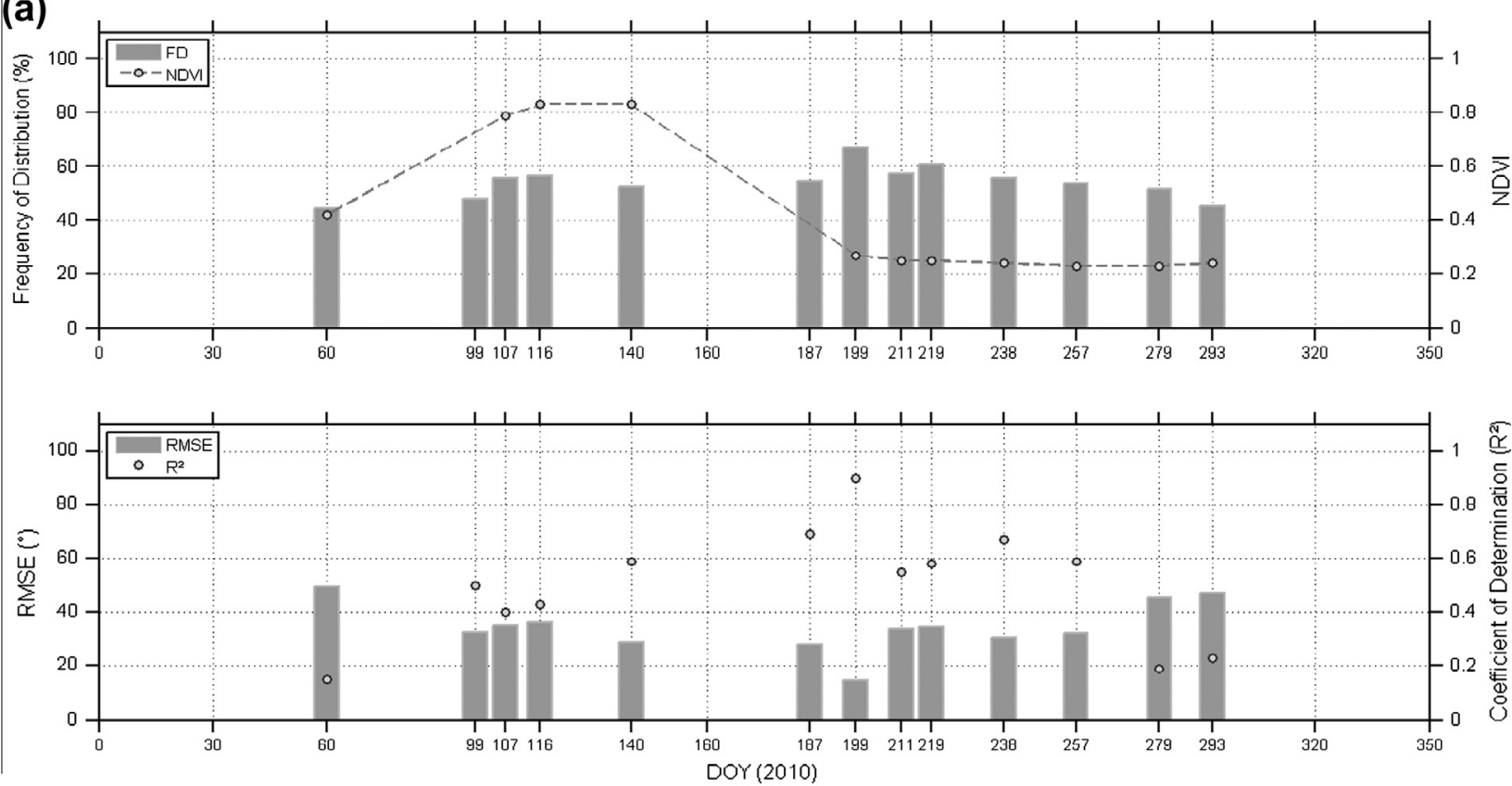

(b)
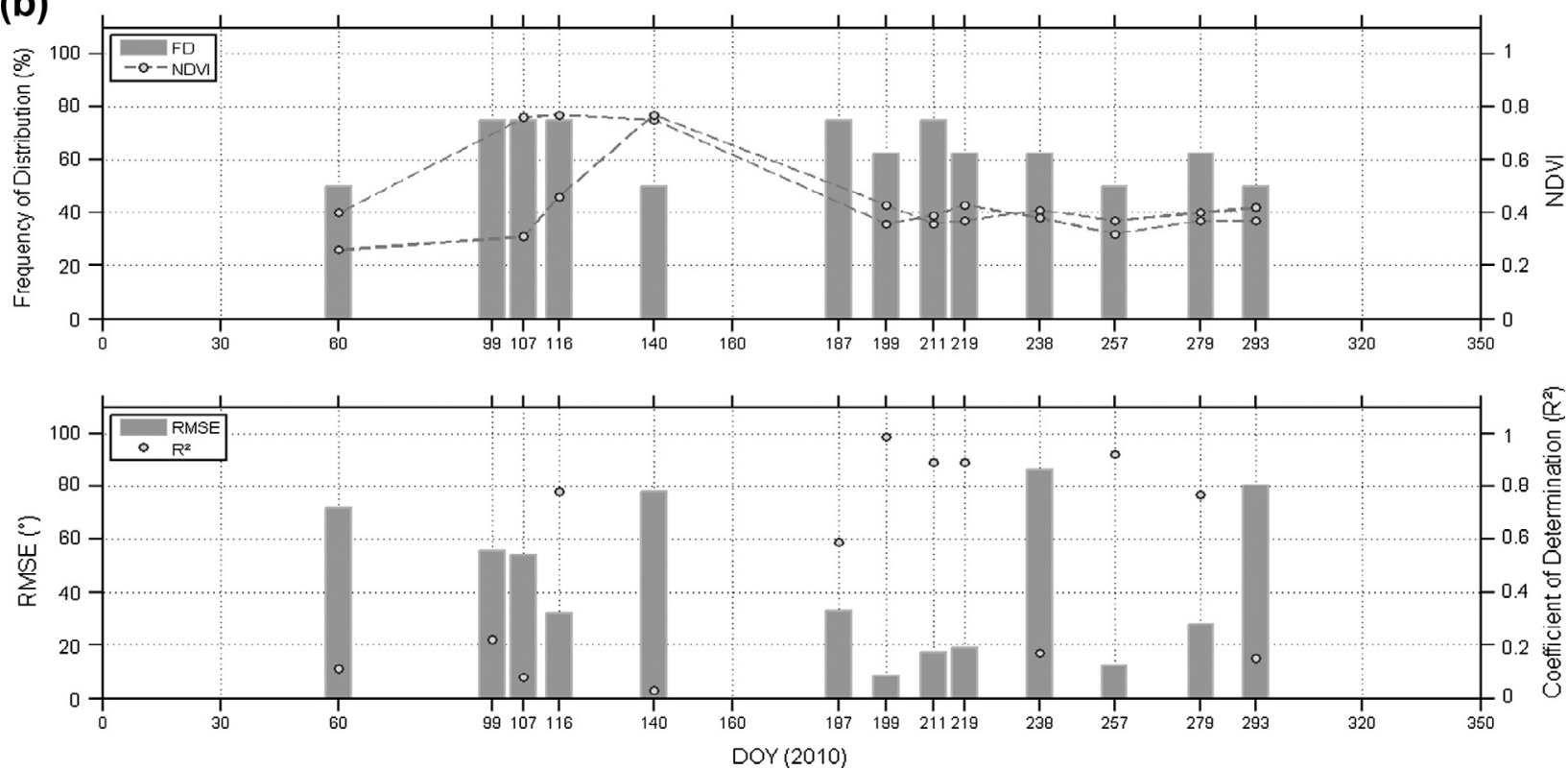

Fig. 12. Temporal evolution of frequency distribution (FD) and NDVI of wheat (a) and winter/spring spring barley (b), together with coefficient of determination, root mean square error (RMSE).

(70\%) have already been harvested (inter-crop phase with or without the presence of stubble). For some winter crops, tilling is carried out with partial burying of the stubble.

\subsubsection{Importance of the spatial frequency}

For each plot, unique azimuth estimation is retained depending on the spatial frequency. To reduce the false detection of orientation, related to intra-land-plot heterogeneities, each spatial frequency of each plot is compared to the median of all spatial frequency observed for the 232 plots. Only the plots for which the spatial frequency is greater than the value of the median are retained. This method allow reducing the relative error (from $48 \%\left(35^{\circ}\right)$ to $\left.20 \%\left(14.5^{\circ}\right)\right)$ and significantly improves the coefficient of determination from 0.56 to 0.90 ), as shown in Fig. 10 .

\subsubsection{Influence of the crop type}

Table 3 displays statistical indexes computed by considering individual, summer, winter or all crops. In this table, the frequency of distribution $(F D)$ represents the relative number of plots for which the method is applied. With a coefficient of determination of 0.90 and a relative error close to $20 \%\left(14.6^{\circ}\right)$, the crop row orientation of all crops can be considered as well estimated for $50 \%$ of plots $(F D=50 \%)$. Similar correlations are obtained for summer $\left(R^{2}=0.91\right.$ and $\left.F D=66 \%\right)$ and winter crops $\left(R^{2}=0.90\right.$ and $F D=19.2 \%$ ). According to the individual crops, the values of coefficient of determination are high with values superior or equal to 0.87 , and orientation errors inferior to $19^{\circ}$. Higher errors are observed for rapeseed $\left(R M S E=16.0^{\circ}\right)$ and sunflower $\left(R M S E=18.5^{\circ}\right)$, explained by the heterogeneity of these crops. Although the number of corn and sunflower plots for 

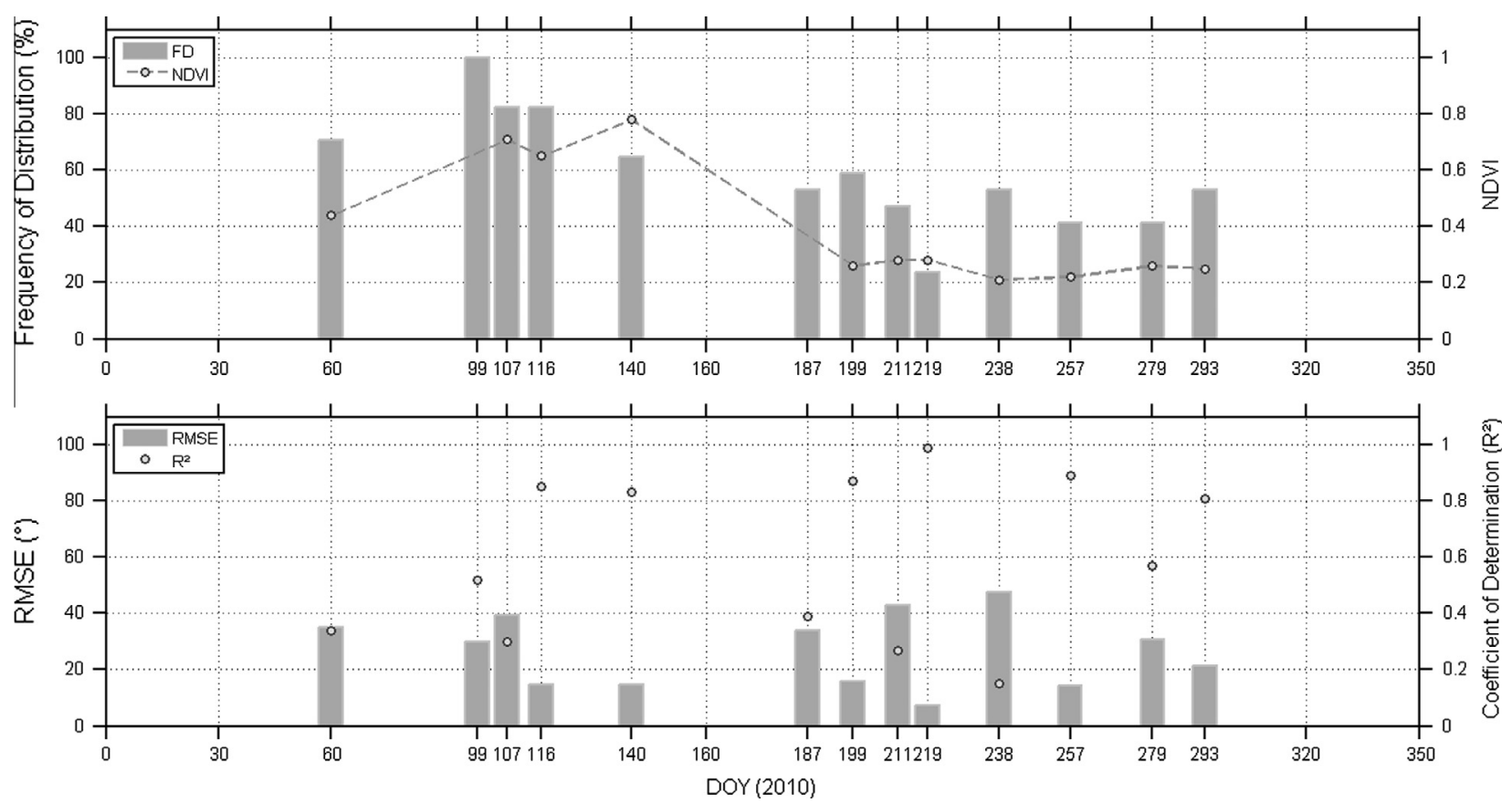

Fig. 13. Temporal evolution of frequency distribution (FD), NDVI, RMSE and $R^{2}$ estimated on rapeseed.
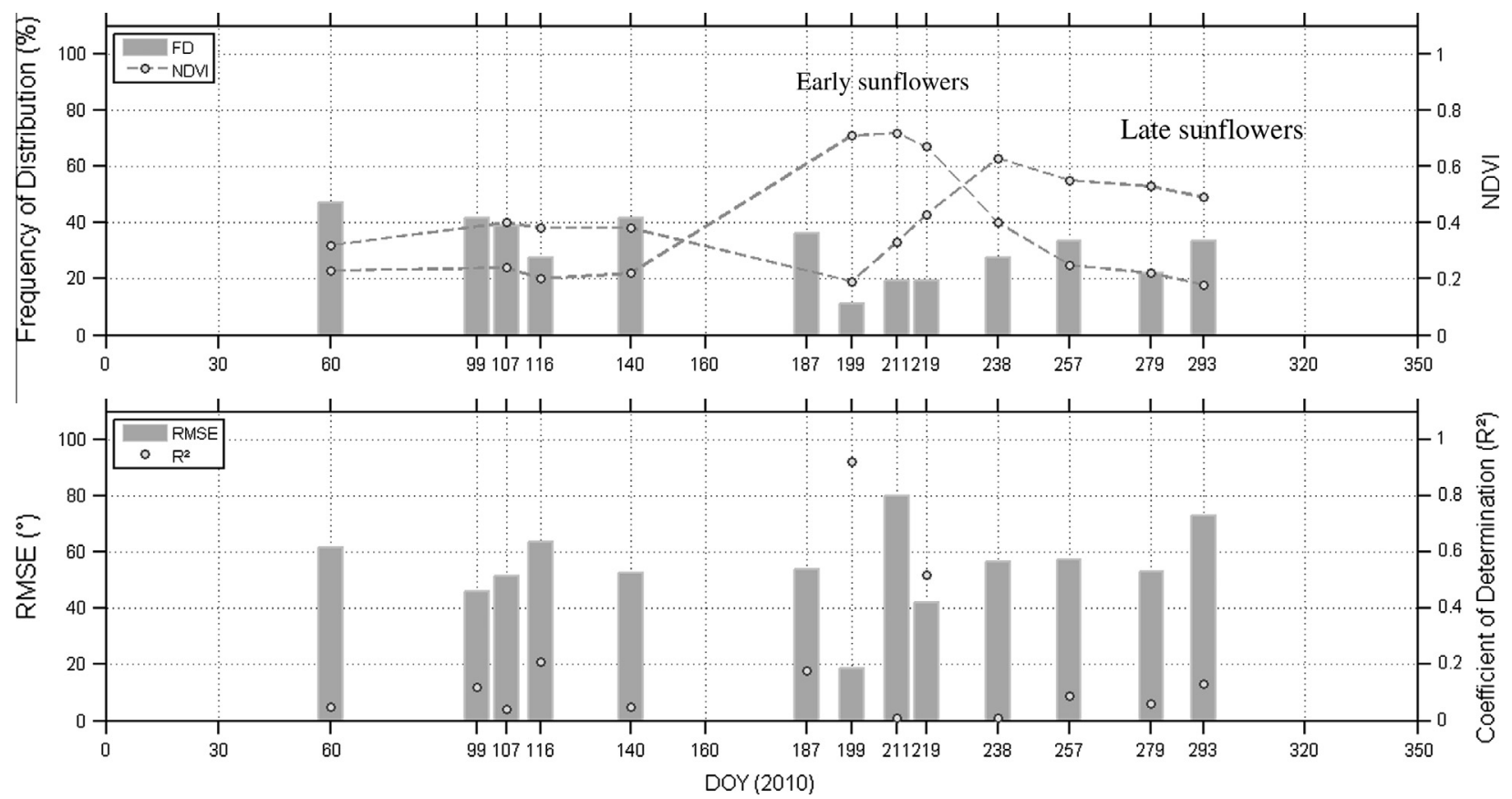

Fig. 14. Temporal evolution of frequency distribution (FD), NDVI, RMSE and $R^{2}$ estimated on early and late sunflowers.

which the orientations is detected is low $\left(F D_{\text {corn }}=22.2 \%\right.$ and $\left.F D_{\text {sunflower }}=11.1 \%\right)$, contrary to the case of hemp ( $F D=71.4 \%$ ), the threshold on the spatial frequency allows the effect of false detections to be avoided $\left(0.92<R^{2}<0.99\right)$.

\subsection{Multi-temporal analysis}

In terms of the crop calendar, the use of multi-temporal series makes it possible to determine the most suitable periods (or date) for distinguishing row orientations, in accordance with the surface state. In fact, several factors may lead to a radiometric change indicative of the orientation (plant's geometry, vegetation cover, distance inter-row, tractor wheel marks, overlapping of agricultural tools, swaths, etc.). The aim of the multi-temporal usage is to take full advantage of all surface changes of the agricultural plots, in order to improve the accuracy with which the row orientations are estimated.

Fig. 11 shows that the period of active vegetation, between midMarch and mid-September, is the most suitable for the determination of the row orientation. For all crops, the coefficient of determination lies between 0.13 (21st of October) and 0.90 (19th of July), with quadratic errors equal to $51.01^{\circ}$ and $14.56^{\circ}$, respectively. The 

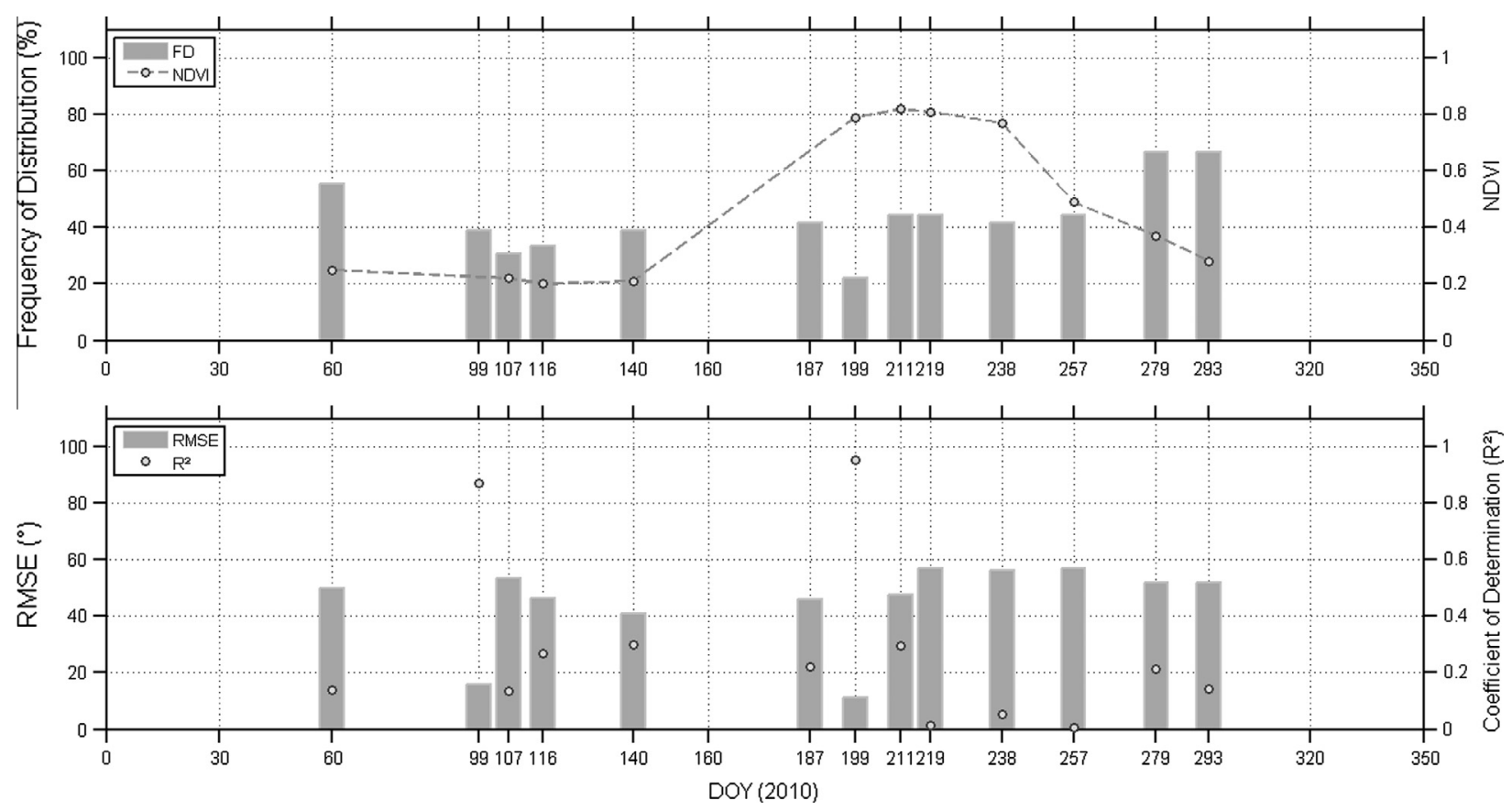

Fig. 15. Temporal evolution of frequency distribution (FD), NDVI, RMSE and $R^{2}$ estimated on corn.

(a)

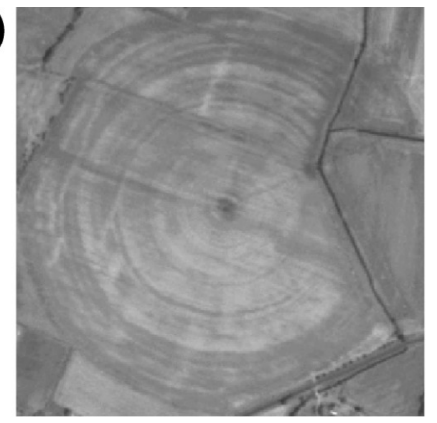

(b)

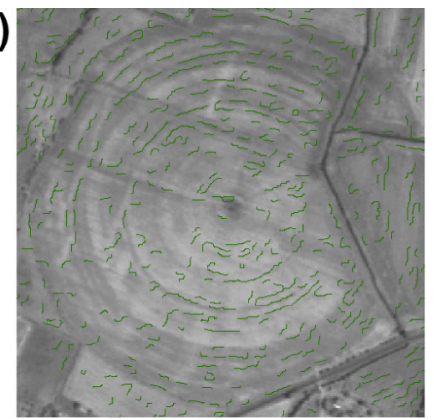

(c)

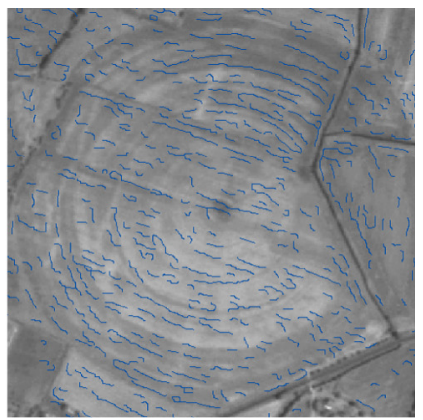

Fig. 16. Impact of pivot irrigation on the estimation of crop row orientation on one maize plot. The panchromatic image is taken on July 19 th (NDVI $=0.8$ ) (a).Two directional filters are applied: $45^{\circ}$ and $135^{\circ}$ (b and c).

weak correlation observed at the beginning of spring or in autumn $\left(R^{2}<0.3\right)$ is associated to the land cover type. At this period, the soil is mainly bare and smooth (about $10 \%$ of deep tillage) or covered by low vegetation, for which the spatial resolution of the images $(2 \mathrm{~m})$ does not allow the good estimation of the row orientation.

\subsubsection{Estimation of row orientation of winter crops}

The coefficients of determination for wheat and barley respectively vary between 0.15 and 0.90 , and between 0.03 and 0.99 (Fig. 12). The trends are furthermore similar, with minima observed during the growing period (when the vegetation cover is the highest) and maxima at harvest time (Fig. 12). In the case of wheat, this period extends until July. In the case of barley, it is longer as a result of the type of barley monitored (winter and spring cultivars). The best results are obtained on July 19th just after harvest where the row orientation is determined for $67 \%$ of the wheat plots, and $62 \%$ of the barley plots. The relative errors are equal to $21 \%\left(15^{\circ}\right)$ for wheat and $11 \%\left(8^{\circ}\right)$ for barley. The coefficients of determination are greater than or equal to 0.90 . The autumn is also a suitable period for the detection of the row orientations for wheat or barley $\left(0.42<R^{2}<0.75\right.$ in mean $)$, thanks to the deep tillage carried out before sowing of the winter crops of 2011 (Fig. 12). These tillages occur on days 238 and 257 for rapeseed and on days 257 and 279 for wheat or barley due to difference in crop calendar.

In the case of rapeseed, the coefficient of determination varies between 0.15 and 0.99 . Fig. 13 shows that the smallest errors occur over two different periods $\left(R M S E<20^{\circ}\right)$. The first phase, from the flowering period until harvesting, lasts from April until July (doy 116 and 140, Fig. 13). During this period, the seedpods are filled and both the vegetation cover and plant geometry are strongly modified, inducing a well-marked radiometric change on satellite image. More than $60 \%$ of the plots of rapeseed are well detected at this period $(60 \%<F D<80 \%$ between doy 116 and 140$)$. The second phase appears during tillage (after doy 238), which precedes the winter crops of 2011.

As for the case of wheat and barley, July 19th is a good date for rapeseed, in terms of the relative error with $24 \%\left(16^{\circ}\right)$, coefficient of determination $\left(R^{2}=0.87\right)$ and frequency distribution $(F D=59 \%)$. This result confirms the well-marked effect of harvest on the capabilities of row orientation detection (due to residues, swath, etc.). In fact, the width of the cutter bar on the combine harvesters lies between 5 and $9 \mathrm{~m}$, which correspond to the estimated lineament spacing, which has a mean value of $7 \mathrm{~m}$. 

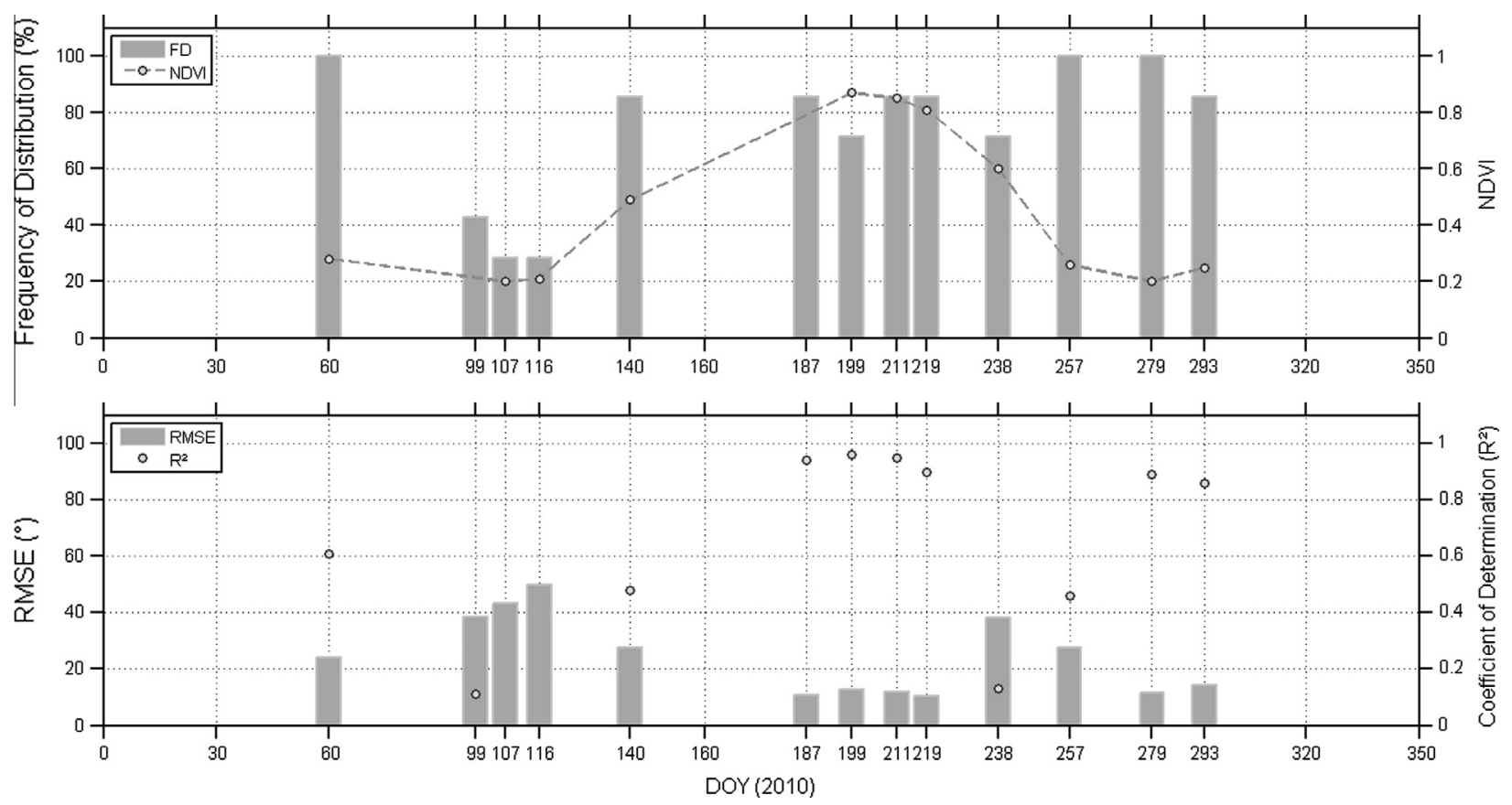

Fig. 17. Temporal evolution of frequency distribution (FD), NDVI, RMSE and $R^{2}$ estimated on hemp.

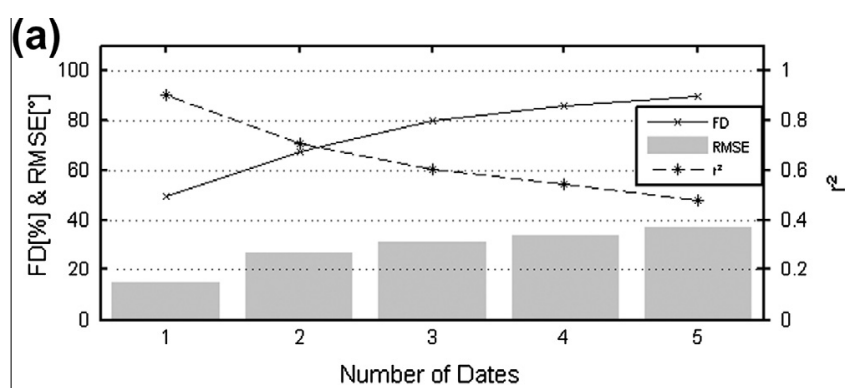

(b)

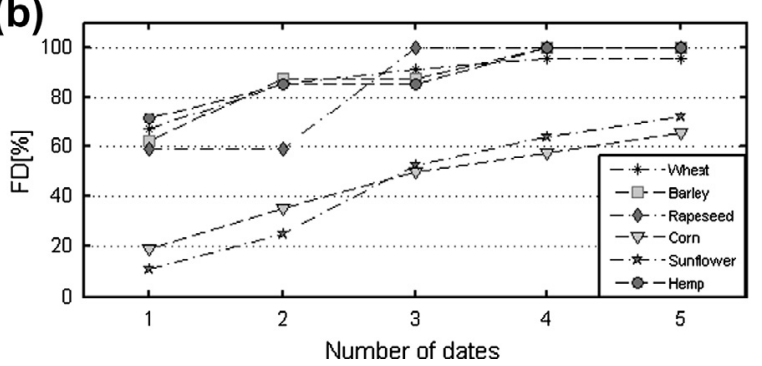

Fig. 18. Evolution of statistical parameters resulting from the use of five dates for all crops (RMSE, $R^{2}$ and $F D$ ) (a). The evolution of the frequency distribution is plotted, by type of crop, as a function of the number of images used (from 1 to 5 ).

\subsubsection{Estimation of row orientation of summer crops}

In 2010, the important spring rains delayed the growth of some summer crop seedlings. The emergence phase was thus spread over several weeks, and in mid-July the plants were characterized by contrasted levels of development.

Fig. 14 shows that the technique has a limited ability to determine the mean sunflower row orientation. However, during the flowering period, on July 19th (doy 199) for the earliest sunflower and on August 8th (doy 219) for the latest, the estimations are more relevant. At these two dates, the coefficients of determination are respectively equals to 0.92 and 0.52 , with a relative error equal to $31 \%\left(18^{\circ}\right)$ and $61 \%\left(42^{\circ}\right)$. Less than $20 \%$ of sunflower plots are detected at these dates $(F D=11 \%$ on 19 th of July and $F D=19 \%$ on 8th of August). This outcome confirms the limitations of this technique (plot approach), in view of the heterogeneity inherent to this type of crop. An intra-land-plot method should be more relevant for this type of crop. No significant results are obtained in autumn since deep tillage events occur later in the year for these plots.

The determination of the row orientation of corn is highly variable ( $R^{2}$ ranged from 0 to 0.95$)$. Two favorable dates can nevertheless be distinguished (Fig. 15). On July 19th, during flowering, 22\% of the corn plots are detected and the coefficient of determination reaches 0.95 , with a relative error inferior to $13 \%\left(12^{\circ}\right)$. April 10 th (doy 99) also provides good results, with a coefficient of determination equal to 0.87 (during the tillage prior to the seedlings), associated to a low relative error $\left(18 \%, 16^{\circ}\right)$. On this date, row orientation is estimated for $39 \%$ of the corn plots.

This variability of detection is partly related to the presence of irrigation equipment, which can present different orientation to that of the seedlings on the plot. The extent to which the soil and ruts are compacted, due to the presence of irrigation ramps, affects the detection process and/or leads to weak estimations capabilities. Fig. 16 shows that the irrigation equipment, like pivots, tends to adversely affect the detection of the row orientations of irrigated crops by creating a directional heterogeneity. As for sunflower, an intra-land-plot method should be more relevant.

The determination of the row orientation for the hemp crops is particularly interesting, on account of the significant vegetation cover produced by this crop. Fig. 17 shows that the coefficient of determination varies between 0.11 and 0.96 , and follows the NDVI cycle. Throughout the period for which the NDVI reaches maximum values (NDVI $>0.7$ ), the determination of row orientations is clearly relevant, with a coefficient of determination greater than or equal to 0.90 and a relative error inferior to $15 \%\left(12.6^{\circ}\right)$. During this period, more than $70 \%$ of the plots can be detected $(71 \%<F D<86 \%)$. At the time of senescence, the coefficient of determination is low $\left(R^{2}=0.13\right)$. Then, it increases after harvest ( 2 plots are harvested on September 15th (doy 257), and 5 from the 7th of October (doy 279 and 293 on the Fig. 16), when stubbles are still present on the plot. 


\subsection{Extrapolation of the row orientation to the full scene}

The studied zone, defined as super-site in Fig. 1, comprises 42,320 ha of cultivated lands, including $20 \%$ of grasslands. The extrapolation of the technique to the full scene requires the restoration of a land plot inside the whole study site (Section 4.3.1). Five images are used to estimate and map the row orientation (Sections 4.3.2 and 4.3.3).

\subsubsection{Restoration of plots}

The plot restoration technique is based on the radiometric segmentation of the $8 \mathrm{~m}$ resolution multispectral images. The ability to render the outlines of the plots is better using the four spectral bands of those images (blue, green, red and near infra red), in comparison with the panchromatic images, limited to one spectral information. Initially, the local contour detection technique involves scanning the image with a window defining the zone of interest.

The operator proposed by Shen and Castan is applied to the image in order to detect well-marked radiometric transitions (Shen and Castan, 1992). Then, the mathematical (watershed) morphology algorithm allows extracting closed and skeletoned contours (Ranwez and Soille, 2002). Thresholding of the catchment dynamics is applied using the contour power map, thus leading to the production of a hierarchical representation of the different levels of image segmentation (Fjørtoft and Lopès, 1999).

This technique allows creating several levels of segmentation, corresponding to a given threshold. Depending on its spatio-temporal heterogeneity, a segment may correspond to one, several, or even no agricultural plot. In order to minimize the highly heterogeneous zones and the very small segments, the RPG was used to mask the segmentation. Next, only plots with a surface greater than $1000 \mathrm{~m}^{2}$ (0.1 ha) are conserved. The resulting segments are radiometrically homogeneous, allowing intra-plot heterogeneities, which are a limitation to the plot-by-plot approach described above, to be overcome.

\subsubsection{Image selection}

In order to map the full set of orientations for the entire studied zone, five dates are used. These are classified in terms of the relevance of the results obtained by the multi-temporal analysis: $10 / 07 / 19 ; 10 / 08 / 08 ; 10 / 04 / 10 ; 10 / 07 / 07$ and 10/07/31 (Section 4, Fig. 11). For each date, the crop row orientation of a plot is retained:

- if the FS of the plot exceed the median of the FS observed for all the plots on the image,

- and if the crop row orientation of the plot is not previously estimated by another date.

Adding images to determine more row orientation of plots is performed with the detriment of the coefficient of determination ( $R^{2}$ decreases from 0.90 to 0.48 ) and associated errors (RMSE increases from $14^{\circ}$ to $37^{\circ}$ ) as shown in Fig. 18 .

First, the image acquired on July 19th is selected as an orientation reference for $50 \%$ of the land plot (Fig. 18a). When the image acquired on August 8th is added, in the case of winter crop, the coefficient of determination for all plots is greater than

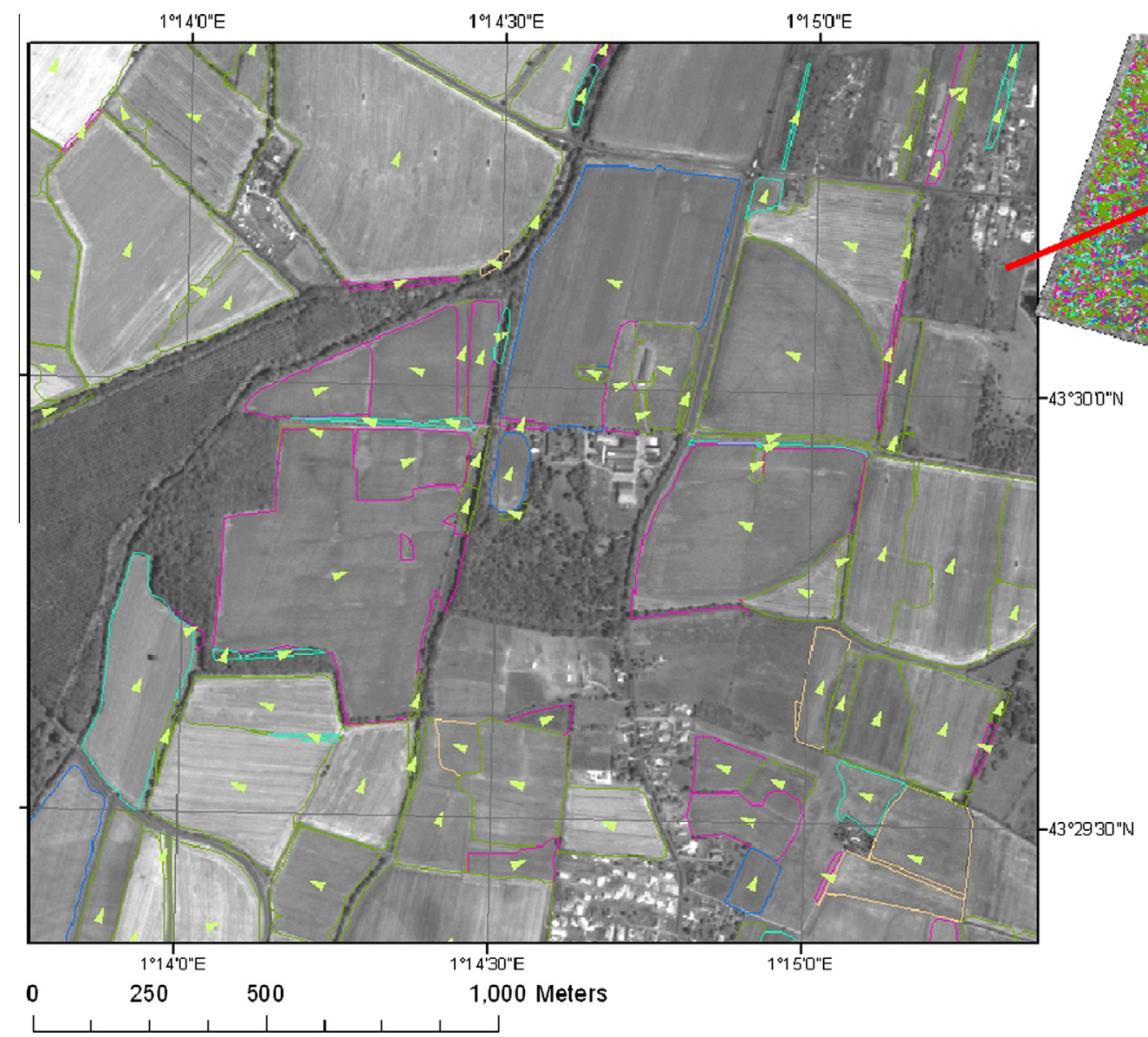

Orientation

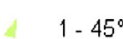

$45-90^{\circ}$

- $90-135^{\circ}$

$135-180^{\circ}$

\section{Confidence Index}

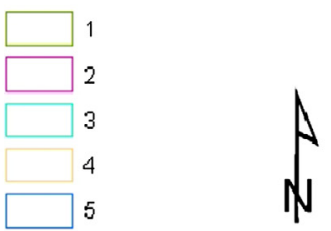

Fig. 19. Row orientation map produced using a multi-temporal approach. Each plot is associated with a confidence index ranging between 1 (high confidence) and 5 (low confidence). 
0.78 , for a number of plots greater than $80 \%(F D=82 \%)$. The coefficient of determination for sunflowers is $0.59\left(\mathrm{RMSE}=38^{\circ}\right)$, but only $25 \%$ of the plots are concerned (Fig. 18b). However, the addition of this image has an adverse effect on corn, since it lowers the coefficient of determination of this crop and increases the error (from $11^{\circ}$ to $47^{\circ}$ ). The use of three dates considerably degrades the coefficient of determination for rapeseed and sunflower, although that corresponding to corn increases slightly, from 0.14 to 0.29 , and the mean error changes from $56^{\circ}$ to $49^{\circ}$. This outcome is related to the date of the image (April 10th, 2010), on which the soil is tilled prior to planting of corn seedlings. Nevertheless, the use of three dates made it possible to determine the orientation of more than $80 \%$ of the land plots, with a mean error of $31^{\circ}$. The addition of the fourth and the fifth dates allowed the orientation of more than $89 \%$ of the land plot to be determined, to the detriment of the accuracy of the results $\left(R^{2}=0.48\right)$ (Fig. 18a and b).

\subsubsection{Mapping the row orientation}

In view of the contributions from each date, mapping of the orientations is carried out with a global confidence index ranging from " 1 " for one single date, to " 5 " when the five dates are taken into account. This confidence index is related to the values of the coefficient of determination estimated in Fig. 18a $\left(R^{2}\right.$ decreases at landscape with the increase of image number). Fig. 19 provides a view of the plots detected over the full footprint of the Formosat2 image, as well as the orientations of a small number of preferred plots.

\section{Conclusion}

The present paper proposes a technique for the extraction of crop rows orientation based on Formosat-2 panchromatic images acquired with a spatial resolution of $2 \mathrm{~m}$. The method developed is based on the use of directional filters and operators taken from binary mathematical morphology. Validation is performed through the use of multi-temporal analysis, on 6 types of crop (232 plots). The quality of the results shows the efficient of the proposed technique over the studied zone (i.e. in a context of moderate surface slopes and a wide range of plot shapes and sizes). This study emphasizes: (i) the importance of the image acquisition dates for the estimation the crop row orientation, whatever the crop type; (ii) the limitations of the method in terms of the extraction of row orientation for plots cultivated with sunflower or corn.

The results obtained for winter crops show that the best estimation period occurs during, or just after the harvesting season. This outcome is attributed to the passage of agricultural machinery together with the presence of stubbles and swaths on the plots. In the case of the determination of summer crop orientations, this depends on the considered type of crop. Although it is relatively straightforward for hemp throughout the period when the NDVI is at a maximum, it remains difficult for the other crops, expected during flowering. Limiting factors related to irrigation adversely affect the detection of corn orientation. In the case of sunflower crops, the limitation arises from the intrinsic heterogeneity of this crop. In the latter two cases, this type of plot-by-plot approach appears to be poorly adapted, with respect to the intra-plot technique, which remains to be evaluated. However, the products generated by this process and the associated confidence indices can be used as a basis for the analysis of agricultural landscapes, with respect to numerous thematic topics such as soil erosion, hydrological approaches, water balances, carbon and energy budget, etc.

This study corresponds to an initiative for the use and the promotion of actual and future high spatial resolution satellite images (delivered by Spot, Formosat, Sentinel or Ven $\mu$ s). The application of this technique on archive satellite data will provide structural information concerning the row orientation of crops during the past years. Future analyses will deal with the use of very high spatial resolution images (delivered by Pleiades, Ikonos or Quickbird) in order to determine the relative contributions of these images for the monitoring of agricultural crop row orientations.

\section{Acknowledgements}

The authors extend their warm thanks to the members of the Kalideos project from the CNES and the "CS système d'information" company, for the panchromatic and multispectral reduction of the satellite images. Many thanks to the farmers for providing all necessary information of their agricultural plots.

\section{References}

Agam, N., Kustas, W.P., Evett, S.R., Colaizzi, P.D., Cosh, M.H., McKee, L.G., 2012. Soil heat flux variability influenced by row direction in irrigated cotton. Adv. Water Res. 50, 31-40.

Amesz, B., Lausink, A., 1984. Satellite sensing aid upper Volta's drilling. World Water, 21-24.

Andrieu, B., Baret, F., Jacquemoud, S., Malthus, T., Steven, M., 1997. Evaluation of an improved version of SAIL model for simulating bidirectional reflectance of sugar beet canopies. Rem. Sens. Environ. 60, 247-257.

Baret, F., de Solan, B., Lopez-Lozano, R., Ma, K., Weiss, M., 2010. GAI estimates of row crops from downward looking digital photos taken perpendicular to rows at 57.5 $\hat{A}^{\circ}$ zenith angle: Theoretical considerations based on 3D architecture models and application to wheat crops. Agri. For. Meteorol. 150, 1393-1401.

Bastiaanssen, W.G.M., Molden, D.J., Makin, I.W., 2000. Remote sensing for irrigated agriculture: examples from research and possible applications. Agri. Water Manage. 46, 137-155.

Baup, F., Fieuzal, R., Marais Sicre, C., Dejoux, J.-F., le Dantec, V., Mordelet, P., Claverie, M., Demarez, V., Hagolle, O., Lopes, A., Keravec, P., Ceschia, E., Merlin, O., Kidd, R. (2012). MCM'10: An experiment for satellite multispectral crop monitoring From high to low resolution observations. In: Geoscience and Remote Sensing Symposium, 2012 IEEE International, IGARSS 2012. Munich, Germany. <http:// www.cesbio.ups-tlse.fr/us/mcm.html>.

Bobillet, W., Da Costa, J.-P., Germain, C., Lavialle, O., Grenier, G. (2003). Row detection in high resolution remote sensing images of vine fields. In: European Conference on Precision Agriculture, Berlin Germany.

Boissard, P., Pointel, J.G., Tranchefort, J., 1992. Estimation of the ground cover ratio of a wheat canopy using radiometry. Int. J. Rem. Sens. 13, 1681-1692.

Bossu, J., Gee, C., Jones, G., Truchetet, F., 2009. Wavelet transform to discriminate between crop and weed in perspective agronomic images. Comput. Electron. Agri. 65, 133-143.

Brunn, A., Weidner, U., 1998. Hierarchical Bayesian nets for building extraction using dense digital surface models. ISPRS J. Photogram. Rem. Sens. 53, 296-307.

Burgos-Artizzu, X.P., Ribeiro, A., Tellaeche, A., Pajares, G., Fernandez-Quintanilla, C., 2011. Analysis of natural images processing for the extraction of agricultural elements. Image Vision Comput. 28, 138-149.

Callot, Y., Mering, C., Simonin, A., 1993. Quantification et cartographie par télédétection des aires dunaires sur les images SPOT panchromatiques à partir des méthodes de la morphologie mathématique. Bull. Inst. Géol. Bassin d'Aquitaine, Bordeaux 53, 221-232.

Champion, I., Faivre, R., 1996. The field row direction relative to the radar azimuth considered as an apparent surface roughness for smooth bare soils. Int. J. Rem. Sens. 17/16, 3305-3311.

Chern, J.S., Wu, A.M., Lin, S.F., 2006. Lesson learned from FORMOSAT-2 mission operations. Acta Astronautica 59, 344-350.

Claverie, M., Demarez, V., Duchemin, B., Hagolle, O., Ducrot, D., Marais Sicre, C., Dejoux, J.-F., Huc, M., Keravec, P., Béziat, P., Fieuzal, R., Ceschia, É., Dedieu, G., 2012. Maize and sunflower biomass estimation in southwest France using high spatial and temporal resolution remote sensing data. Rem. Sens. Environ. 124, 844-857.

Dabrowska-Zielinska, K., Gruszczynska, M., Kowalik, W., Stankiewicz, K., 2002. Application of multisensor data for evaluation of soil moisture. Adv. Space Res. 29, 45-50.

Denoroy, P., Justes, E., Goss, G., 2000. Mesure du taux de couverture du sol pour estimer les principales caractéristiques d'une culture de colza avant montaison. Oléagineux, Corps Gras, Lipides 7 (1), 118-123.

Dobson, M.C., Ulaby, F., 1981. Microwave backscatter dependence on surface roughness, soil moisture, and soil texture: Part III-soil tension. geoscience and remote sensing. Geosci. Rem. Sens., IEEE Trans. on, GE-19, 51-61.

Dobson, M.C., Ulaby, F.T., Pierce, L.E., 1995. Land-cover classification and estimation of terrain attributes using synthetic aperture radar. Rem. Sens. Environ. 51, $199-214$.

Duchemin, B., Hadria, R., Erraki, S., Boulet, G., Maisongrande, P., Chehbouni, A., Escadafal, R., Ezzahar, J., Hoedjes, J.C.B., Kharrou, M.H., Khabba, S., Mougenot, B., Olioso, A., Rodriguez, J.C., Simonneaux, V., 2006. Monitoring wheat phenology and irrigation in Central Morocco: on the use of relationships between 
evapotranspiration, crops coefficients, leaf area index and remotely-sensed vegetation indices. Agri. Water Manage. 79, 1-27.

Duchemin, B., Maisongrande, P., Boulet, G., Benhadj, I., 2008. A simple algorithm for yield estimates: Evaluation for semi-arid irrigated winter wheat monitored with green leaf area index. Environ. Model. Soft. 23, 876-892.

Fieuzal, R., Baup, F., Marais Sicre, C., (2012). Sensitivity of TERRASAR-X, RADARSAT2 and ALOS satellite data to crop variables. In: Geoscience and Remote Sensing Symposium, 2012 IEEE International, IGARSS 2012. Munich, Germany.

Fieuzal, R., Baup, F., Marais Sicre, C., 2013. Monitoring wheat and rapeseed by using synchronous optical and radar satellite data-from temporal signatures to crop parameters estimation. Adv. Rem. Sens. 2 (2), 162-180.

Fjørtoft, R., Lopès, A., 1999. Estimation of the mean radar reflectivity from a finite number of correlated samples. Geosci. Rem. Sens. (TGARS).

Gaillard C., (2001). Amélioration d'un modèle d'érosion hydrique pour la prise en compte spatiale de l'influence anthropique en milieu agricole. Thèse de doctorat, Département de géographie et télédétection, Université de Sherbrooke, Québec, Canada, Directeur F. Bonn, p. 178.

Gée, C., Bossu, J., Jones, G., Truchetet, F., 2008. Crop/weed discrimination in perspective agronomic images. Comput. Electron. Agri. 60, 49-59.

Guerrero, J.M., Guijarro, M., Montalvo, M., Romeo, J., Emmi, L., Ribeiro, A., Pajares, G. 2013. Automatic expert system based on images for accuracy crop row detection in maize fields. Exp. Syst. Appl. 40, 656-664.

Hadria, R., Duchemin, B., Baup, F., Le Toan, T., Bouvet, A., Dedieu, G., Le Page, M., 2009. Combined use of optical and radar satellite data for the detection of tillage and irrigation operations: case study in Central Morocco. Agri. Water Manage. 96, 1120-1127.

Hague, T., Tillett, N.D., 2001. A bandpass filter-based approach to crop row location and tracking. Mechatronics 11, 1-12.

Jenness, J., (2011). Tools for Graphics and Shapes: Extension for ArcGIS. Jenness Enterprises. Available at: <http://www.jennessent.com/arcgis/shapes_graphics.htm>.

Jin, X., Davis, C., 2005. Automated building extraction from high-resolution satellite imagery in urban areas using structural, contextual, and spectral information. EURASIP J. Appl. Signal Process. 14, 2196-2206.

Jishuang, Q., Chao, W., (2002). A multi-threshold based morphological approach for extracting coastal line feature in remote sensing. In: Proceedings of the ISPRS Commission I Symposium on Integrated Remote Sensing at the Global, Regional andLocal Scale, IAPRS.

Jones, G., Gee, C., Truchetet, F., 2009. Assessment of an inter-row weed infestation rate on simulated agronomic images. Comput. Electron. Agri. 67, 43-50.

Kimes, D.S., Kirchner, J.A., 1983. Diurnal variations of vegetation canopy structure. Int. J. Rem. Sens. 4, 257-271.

Laporterie, F., Flouzat, G., Amram O., (2001). Mathematical morphology multilevel analysis of trees patterns in Savannas. In: Proceedings of the IEEE International Geoscience and Remote Sensing Symposium (IGARSS'01), Sydney, Australia, pp. 1496-1498.

Latouche, R., (1967). Etudes médiévaless: le haut moyen Age. La France de l'Ouest Des Pyrénées aux Alpes. Cahiers de civilisation médiévale, 486-486.

Liu, J.G., Pattey, E., Miller, J.R., McNairn, H., Smith, A., Hu, B.X., 2010. Estimating crop stresses, aboveground dry biomass and yield of corn using multi-temporal optical data combined with a radiation use efficiency model. Rem. Sens. Environ. 114, 1167-1177.

Lobell, D.B., Asner, G.P., Ortiz-Monasterio, J.I., Benning, T.L., 2003. Remote sensing of regional crop production in the Yaqui Valley, Mexico: estimates and uncertainties. Agri. Ecosyst. Environ. 94, 205-220.

Loseen, D., Mougin, E., Rambal, S., Gaston, A., Hiernaux, P., 1995. A regional sahelian grassland model to be coupled with multispectral satellite data.2. toward the control of its simulations by remotely-sensed indexes. Rem. Sens. Environ. 52 194-206.

Maire, É., Sicre, Marais C., Guillerme, S., Rhoné, F., J.-F.Dejoux, Dedieu, G., 2012 Télédétection de la trame verte arborée en haute résolution par morphologie mathématique. Revue Internationale de Géomatique 22 (4), 519-538.

Marchant, J.A., 1996. Tracking of row structure in three crops using image analysis. Comput. Electron. Agri. 15, 161-179.

Matti-Gallice, C., Collet, C., (2004). Morphologie mathématique et échelle. Extraction du bâti à différentes résolutions spatiales. Revue internationale de Géomatique., 14/3-4, 441-463.
Mavrantza, O.D., Argialas, P.D., 2003. Implementation and evaluation of spatial filtering and edge detection techniques forlineament mapping - case study: Alevrada, Central Greece. In: SPIE International Conference on Remote Sensing: Remote Sensing for Environmental Monitoring, GIS Applications, and Geology II. Bellingham, WA, pp. 417-428.

Mc Nairn, H., Champagne, C., Shang, J., Holmstrom, D., Reichert, G., 2009. Integration of optical and Synthetic Aperture Radar (SAR) imagery for delivering operational annual crop inventories. ISPRS J. Photogram. Rem. Sens. 64, 434449.

Meier, U., (2001). Stades phénologiques des mono-et dicotylédones cultivées. Centre Fédéral de Recherches Biologiques pour l'Agriculture et les Forêts.

Montalvo, M., Pajares, G., Guerrero, J.M., Romeo, J., Guijarro, M., Ribeiro, A., Ruz, J.J., Cruz, J.M., 2012. Automatic detection of crop rows in maize fields with high weeds pressure. Exp. Syst. Appl. 39, 11889-11897.

Moran, M.S., Alonso, L., Moreno, J.F., Pilar Cendrero Mateo, M., Fernando de la Cruz, D. Montoro, A., 2012. A RADARSAT-2 Quad-Polarized Time Series for Monitoring Crop and Soil Conditions in Barrax, Spain. Geosci. Rem. Sens., IEEE Trans 50, 1057-1070.

Olsen, H.J., 1995. Determination of row position in small-grain crops by analysis of video images. Comput. Electron. Agri. 12, 147-162.

Rabaute, T., Tinel, C., Marzocchi, Polizzi S., De Boissezon, H., 2012. Kalidéos, des images pour la science: un instrument au service des applications thématiques. Revue Française de Photogrammétrie et de Télédétection 197, 3-9.

Ranwez, V., Soille, P., 2002. Order independent homotopic thinning for binary and grey tone anchored skeletons. Patt. Recog. Lett. 23, 687-702.

Seelan, S.K., Laguette, S., Casady, G.M., Seielstad, G.A., 2003. Remote sensing applications for precision agriculture: a learning community approach. Rem. Sens. Environ. 88, 157-169.

Serra, J., analysis, Image, morphology, mathematical, 1988. Theoret. Adv. 2, 411.

Sheeren, D., Lefèvre, S., Weber, J., (2007). La morphologie mathématique binaire pour l'extraction automatique des bâtiments dans les images THRS. Revue internationale de Géomatique, 17 - $\mathrm{n}^{\circ} 3-4,333-352$

Shen, J., Castan, S., 1992. An optimal linear operator for step edge detection. CVGIP Graph. Models Image Process. 54, 112-133.

Sogaard, H.T., Olsen, H.J., 2003. Determination of crop rows by image analysis without segmentation. Comput. Electron. Agri. 38, 141-158.

Turner, M.G., 1989. Landscape ecology: the effect of pattern on process. Annu. Rev. Ecol. Syst. 20, 171-197.

Ulaby, F.T., Bare, J.E., 1979. Look direction modulation function of the rada backscattering coefficient of agricultural fields. Photogram. Eng. Rem. Sens. 45, 1495-1506.

Ulaby, F.T., Allen, C.T., Eger Iii, G., Kanemasu, E., 1984. Relating the microwave backscattering coefficient to leaf area index. Rem. Sens. Environ. 14, 113-133.

Valero, S., Chanussot, J., Benediktsson, J.A., Talbot, H., Waske, B., 2010. Advanced directional mathematical morphology for the detection of the road network in very high resolution remote sensing images. Patt. Recog. Lett. 31, 1120-1127.

Wessels, K.J., Prince, S.D., Zambatis, N., Macfadyen, S., Frost, P.E., Van Zyl, D., 2006. Relationship between herbaceous biomass and 1-km(2) Advanced Very High Resolution Radiometer (AVHRR) NDVI in Kruger National Park, South Africa. Int. J. Rem. Sens. 27, 951-973.

Wu, X., Xu, W., Song, Y., Cai, M., 2011. A detection method of weed in wheat field on machine vision. Proc. Eng. 15, 1998-2003.

Zall, O., Russel, O., 1979. Ground water exploration programs in Africa. Satellite Hydrology, Am. water Res. Assoc. 5, 416-425.

Zhang, C., Murai, S., \& Baltsavias, E.P., (1999). Road network detection by mathematical morphology. Bulletin de la S.F.P.T., 153, 94-96.

Zhao, F., Gu, X., Verhoef, W., Wang, Q., Yu, T., Liu, Q., Huang, H., Qin, W., Chen, L. Zhao, H., 2010. A spectral directional reflectance model of row crops. Rem. Sens. Environ. 114, 265-285.

Zheng, X., Gong, P., Strome, M., 1995. Characterizing spatial structure of tree canopy using color photographs and mathematical morphology. Canad. J. Rem. Sens. 21 (4), 420-428. 